The University of San Francisco

USF Scholarship: a digital repository @ Gleeson Library |

Geschke Center

Environmental Science

College of Arts and Sciences

1997

\title{
Detecting Fire and Grazing Patterns in Tallgrass Prairie Using Spectral Mixture Analysis
}

Carol A. Wessman

C Ann Bateson

Tracy Benning

University of San Francisco, tlbenning@usfca.edu

Follow this and additional works at: http://repository.usfca.edu/envs

Part of the Environmental Sciences Commons

\section{Recommended Citation}

Carol A. Wessman, C. Ann Bateson, and Tracy L. Benning 1997. DETECTING FIRE AND GRAZING PATTERNS IN TALLGRASS PRAIRIE USING SPECTRAL MIXTURE ANALYSIS. Ecological Applications 7:493-511.

This Article is brought to you for free and open access by the College of Arts and Sciences at USF Scholarship: a digital repository @ Gleeson Library | Geschke Center. It has been accepted for inclusion in Environmental Science by an authorized administrator of USF Scholarship: a digital repository @ Gleeson Library | Geschke Center. For more information, please contact repository@usfca.edu. 


\title{
DETECTING FIRE AND GRAZING PATTERNS IN TALLGRASS PRAIRIE USING SPECTRAL MIXTURE ANALYSIS
}

\author{
Carol A. Wessman, ${ }^{1,2}$ C. Ann Bateson, ${ }^{2}$ and Tracy L. Benning ${ }^{3}$ \\ ${ }^{1}$ Environmental, Population and Organismic Biology, University of Colorado, Boulder, Colorado 80309-0216 USA \\ ${ }^{2}$ Cooperative Institute for Research in Environmental Sciences, University of Colorado, Boulder, \\ Colorado 80309-0216 USA \\ ${ }^{3}$ Department of Biological Sciences, Stanford University, Stanford, California 94305 USA
}

\begin{abstract}
Global grasslands are typically under management practices (such as fire and grazing) that alter nutrient cycling, ecosystem composition, and distribution of organic matter from the unmanaged condition. We evaluated landscape-level response to fire and grazing treatments in the Konza Tallgrass Prairie Research Natural Area, Kansas, using spectral mixture analysis of Airborne Visible/Infrared Imaging Spectrometer (AVIRIS) data acquired 31 August 1990. Spectral mixture analysis derives the fractional abundances of spectrally unique components in the landscape. The reflectance spectra of these components are called endmembers. Endmember fractions values were compared against ground values of live biomass, current standing dead biomass, and litter for 12 watersheds. Analysis of variance (ANOVA) was performed on 37 watersheds with known burning and grazing histories for each of the remote sensing variables. Seven endmembers were selected from the AVIRIS data using a manual endmember selection method: nonphotosynthetic vegetation (NPV), soil, rock, shade, and three green vegetation endmembers (GV1, GV2, and GV3). Each vegetation endmember correlated differently to biomass measurements and revealed unique relationships to management treatments. From regressions, ANOVAs, and image analysis, these three endmembers were inferred to represent canopy vertical structure or leaf area index (LAI), greenness, and fractional cover of grass, respectively. There was a stronger relationship between the sum of GV1 and GV3 fractions and live grass biomass values than there was with the (unsummed) individual fractions. In an ANOVA, the sum separated both burn and grazing treatments as well as the treatment interaction. The NPV fraction was strongly correlated with ground measurements of litter and standing dead biomass, and significantly separated burn treatments. The soil fraction differentiated grazing treatments, and analysis of the soil fraction image revealed a spatial coherence of grazing patterns along drainages. Similar analyses were perfomed on the Normalized Difference Vegetation Index (NDVI), a commonly used two-band index computed from red and nearinfrared reflectance. NDVI, shown in previous studies to estimate the fraction of photosynthetically active radiation absorbed by green vegetation (FPAR), was a poor indicator of canopy biomass, but it successfully separated fire treatments.

Broad-scale assessment of the state and structure of managed grassland systems requires the identification of several indicator variables. Spectral mixture analysis, unlike NDVI, not only separated treatments but also allowed for the identification of five remotely sensible factors affected by the management treatments, namely, vertical structure, percentage cover or patchiness, greenness, and distribution of soil and litter.
\end{abstract}

Key words: biomass; fire frequency; grasslands; grazing; Konza Tallgrass Prairie; litter; NDVI; non-linear mixing; nonphotosynthetic vegetation; principal component analysis; remote sensing; spectral mixture analysis.

\section{INTRODUCTION}

Large-scale flux estimates of biosphere-atmosphere interactions require that attributes of ecosystem physiology and structure be measured from remote sensing platforms. Ground measurements give a limited assessment of spatial and temporal variability, whereas remotely sensed observations can assist extrapolations to larger scales and better constrain simulated regional and global flux calculations when used to initialize eco-

Manuscript received 4 December 1995; accepted 27 February 1996; final version received 1 April 1996. system models. However, measurements of fundamental vegetation attributes that have been considered in remote sensing science, in particular photosynthetic capacity through estimation of the fraction of photosynthetically active radiation absorbed by green vegetation (FPAR; e.g., Sellers 1985, Bartlett et al. 1990, Sellers et al. 1992), may not apply generally across ecosystems due to variation in physiological response to resource availability and other potentially limiting factors (Chapin et al. 1987, Schimel et al. 1991). This does not negate the power and generality of remote sensing observations for ecosystem science, but rather stresses 
the points that (1) these observations must be well understood to better constrain the ecological variables they measure and (2) a range of remotely sensed variables must be explored to address the large-scale influence of ecosystem properties such as carbon-nitrogen allocation and decomposition in biosphere-atmosphere interactions.

Due to the apparent simplicity of their structure and physiology, grasslands have been the subject of many remote sensing studies aimed at understanding vegetation reflectance properties and their significance to plant and ecosystem processes (e.g., Sellers et al. 1988, Burke et al. 1991, Dyer et al. 1991, Turner et al. 1992, Paruelo et al. 1993, Lauenroth and Paruelo 1995). However, management practices typical in most grasslands (such as burning and grazing) regulate nutrient cycling, ecosystem composition, and distribution of organic matter in ways that deviate from undisturbed systems (Dyer et al. 1991, Hobbs et al. 1991). In addition, most grasslands are in climatic regions with a high degree of seasonal variability that can lead to frequent alterations in ecosystem resource dynamics and the superimposition of management practices adds further variation in resources over time. This transient nature of resource availability in both managed and unmanaged grasslands results in a complexity of ecosystem structure and functioning that can confound estimates of grassland system properties (Seastedt and Knapp 1993). For example, both fire and, to some extent, grazing increase the amount of PAR available to photosynthesizing vegetation through reduction of standing and fallen litter, resulting in increased photosynthetic capacity (Knapp 1984, Knapp and Seastedt 1986). However in times of drought, the presence of a detrital layer in ungrazed, unburned tallgrass prairie reduces the negative effects on net primary production and fluxes of energy and carbon dioxide that would otherwise be experienced in grazed or burned grasslands (Knapp et al. 1993). Further, grazing may alter patterns in aboveground vs. belowground carbon allocation and enhance plant-available nitrogen (Holland and Detling 1990, Dyer et al. 1991), whereas frequent fires may induce nitrogen limitation through a combination of increased belowground production and higher carbonto-nitrogen ratios in plant material (Risser and Parton 1982, Seastedt et al. 1991, Benning 1993, Ojima et al. 1994).

Ecosystem responses to single or combined management strategies in concert with natural fluctuations in resource availability may be difficult to interpret from ground observations alone, but may result in landscape level "integrated" effects detectable through remote sensing analyses. Yet, because of the complex nature of disturbed systems, single factor measurements (e.g., the FPAR associated with the Normalized Difference Vegetation Index [NDVI]) may be insufficient to adequately characterize the ecosystem state and condition. Other analytical tools based on remote sens- ing should be explored with the aim of capturing variation of temporal and spatial response to management practices. These, in turn, can contribute to regional and global estimates of biosphere fluxes by helping to address the significant portion of the earth's surface managed by humans.

In this paper, we show how linear spectral mixture analysis (LSMA) can be applied to a multispectral image of the Konza Prairie Research Area to detect indicators of burning and grazing treatments. Multispectral satellite or airborne imagery consists of reflectance values measured across a number of spectral bands of various widths depending on the sensor type. Each data acquisition is an image of the landscape with a reflectance curve or spectrum associated with each picture unit or pixel. Pixels that are completely covered by one ground material may have a reflectance spectrum that can be identified as the spectral signature of that material. Vegetation, for example, can be spectrally distinguished from senescent vegetation, soil, and rock by chlorophyll's absorption of red wavelengths and by high reflectance of near-infrared (NIR) wavelengths due to leaf and canopy structure (Gates et al. 1965). Often, however, a pixel from a remotely sensed image does not consist of a single material but is a mixture of materials such as vegetation, soil, and senescent vegetation. In this case, its spectrum is the integration by the sensor of the reflectance of several spectrally distinct ground components.

LSMA, which models each spectrum as a mixture of the spectral responses of a finite number of ground components, is used for the analysis of heterogeneous land surfaces. The component spectra used in the model are called endmembers. Because LSMA computes the fractional coverage of each endmember within each pixel, it reveals the horizontal distribution of ground materials in the landscape. In addition, endmembers may be selected so that LSMA also reveals aspects of the vertical structure such as leaf area index (LAI), biomass, and background.

Vertical structure influences spectral reflectance through non-linear mixing that occurs when light comes in contact with more than one ground component before it is reflected back to the sensor (see Fig. 1). For example, part of the light striking a leaf may be transmitted through the leaf and reflected from a bright soil back through the leaf and on to the sensor. The effect of this interaction of the light with both the leaf and the bright soil produces a spectrum different from that of a leaf against a dark soil background (Roberts 1991). Hence, in a vegetated landscape with a patchwork of variable soil brightnesses occurring at the scale of the pixel or greater, more than one vegetation endmember may be needed to accurately compute fractions of vegetation. Also, multiple leaf layers increase the NIR reflectance because NIR radiation is scattered among the layers (Borel and Gerstl 1994, Yoder and Waring 1994). A vegetation endmember with a high 


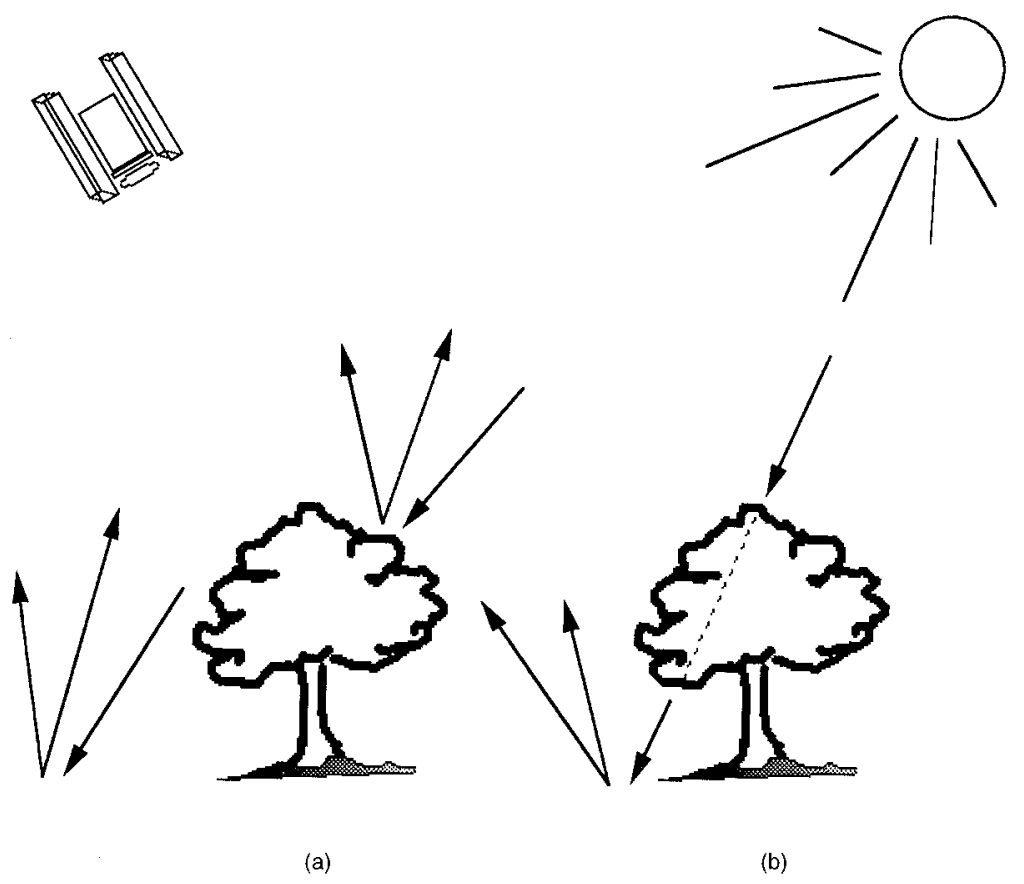

FIG. 1. Illustration of linear and non-linear mixing: (a) linear mixing occurs when the sensor integrates light reflected from more than one source such as soil and leaves, (b) non-linear mixing occurs when light is multiply scattered; that is, the light hits more than one surface before being reflected back to the sensor. In this figure, the light is transmitted through the vegetation canopy, strikes the soil, and is then reflected back to the sensor. These effects impart to the soil reflectance signature a resemblance to the spectral signature of green vegetation (Huete 1989).

NIR plateau should have large fractions in those pixels consisting mainly of dense vegetation; these fractions should be correlated with LAI, which becomes a canopy attribute detectable by LSMA.

Many applications of LSMA have drawn on libraries of laboratory- or field-acquired spectra to develop sets of endmembers (e.g., Smith et al. 1990, Gamon et al. 1993, Roberts et al. 1993, Smith et al. 1994, Adams et al. 1995). Alternatively, a manual endmember selection method (Bateson and Curtiss 1996) has been designed to derive from the image data endmembers whose shapes are influenced by significant non-linear mixing and other factors determining the spectral responses recorded in the dataset. With the derived set of endmembers, the LSMA model can be inverted to produce a suite of variables (i.e., endmember fractions). In this paper, each variable was considered as an indicator of ecosystem response to management practices in the Konza prairie.

We also included NDVI in our analysis of the Konza landscape because it is a familiar tool often used by ecologists in vegetation studies based on remotely sensed data. Simple two-band spectral vegetation indices such as NDVI exploit differences in canopy reflectance in red and near-infrared wavebands to distinguish vegetation from other landscape components. NDVI is a near-linear indicator of PAR interception by the canopy; however, it is a less reliable predictor of structural properties such as LAI and biomass (Sellers
1985, 1987). Recent studies demonstrate a response to chlorophyll concentration independent of LAI (Yoder and Waring 1994) and to green standing biomass when percentage of non-green tissue is removed from the calculations (Gamon et al. 1995). Non-green standing biomass, plant canopy geometry, percentage cover, and variation in background can all influence NDVI's sensitivity to biomass and LAI (e.g., Jackson et al. 1979, Huete et al. 1985, Jackson and Pinter 1986, Huete and Jackson 1987). Because NDVI responds to a complex of structural and functional factors, it was anticipated that conflicting influences at the Konza site could undermine NDVI's tracking of watershed features most indicative of burning and grazing. Moreover, it was not expected that NDVI would clearly track changes in graminoid biomass because there are trees in some of the watersheds (especially, the grazed watersheds) and NDVI responds to trees as well as grass. On the other hand, LSMA has an advantage over single indices such as NDVI because endmembers may be selected to separate and individually track radiative processes and factors contributing to a spectrum and indicative of canopy condition (e.g., LAI and chlorophyll concentration).

The goal of this paper is to show that grazing and fire treatments in the tallgrass prairie of the Konza Research Area result in landscape scale characteristics both indicative of grassland condition and detectable through remote sensing analysis. Ultimately, remotely sensed indicators of the state of managed grasslands 


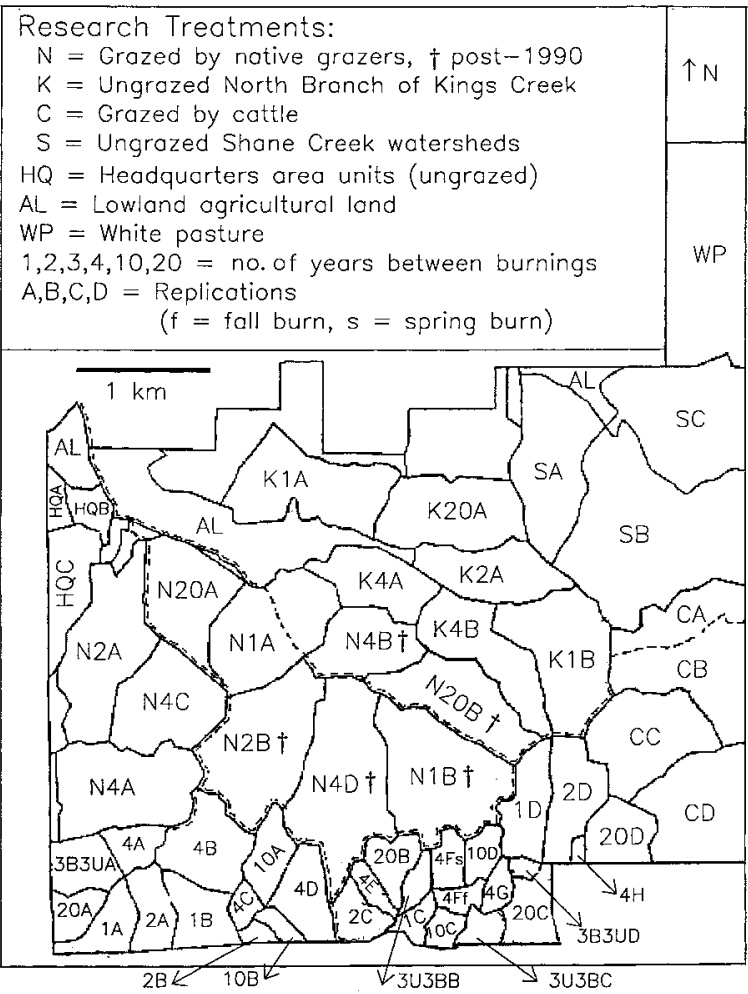

FIG. 2. Map of the Konza Prairie Research Natural Area, Kansas, showing burn and grazing treatments. This map identifies the watersheds described throughout this paper.

can be used to support simulations of grassland dynamics for predictive capability. For example, quantification of the abundance of live vegetation can constrain simulations of a system's potential to acquire resources through photosynthesis and nutrient uptake and to lose water by transpiration. Measurements of dead vegetation or litter cover can constrain decomposition calculations; leaf and stem litter represent major inputs of energy and resources to animals and decomposers.

In our analysis, endmember fractions computed by LSMA and the NDVI values were compared through linear regression to biomass measurements collected by the Long-Term Ecological Research Program at the Konza. Response to the management treatments has been assessed through these annual measurements of net primary production (e.g., Towne and Owensby 1984, Abrams et al. 1986, Hobbs et al. 1991, Vinton et al. 1993). In an extension of the LSMA and NDVI analyses to the rest of the Konza Prairie for which there are no ground data, we perform ANOVAs to ascertain the sensitivity of each endmember and NDVI to treatment types.

\section{Materials and Methods}

\section{The study site}

This study was conducted at Konza Prairie Research Natural Area, a 3487-ha tract of tallgrass prairie located
$10 \mathrm{~km}$ south of Manhattan, Kansas $\left(39^{\circ} 3^{\prime} \mathrm{N}, 96^{\circ} 3^{\prime} \mathrm{W}\right.$; Fig. 2). This site was established in 1970 to study the effects of fire and fire frequency on tallgrass prairie ecosystems and became a member of the U.S. National Science Foundation's Long-Term Ecological Research Network (LTER) in 1980. Subsequently, grazing by native herbivores (bison) as well as cattle has been added to the experimental design. Vegetation in this area is dominated by warm season $\mathrm{C}_{4}$ grasses such as big bluestem (Andropogon gerardii Vitman), little bluestem (Andropogon scoparius Michx.) and Indiangrass (Sorghastrum nutans (L.) Nash.). A more detailed description of vegetation composition is available in Hulbert (1988). Rainfall for the area averages $83 \mathrm{~cm} / \mathrm{yr}$, of which $\approx 75 \%$ occurs in the growing season from April through September; mean January temperature is $-2.7^{\circ} \mathrm{C}$ and mean July temperature is $26.6^{\circ} \mathrm{C}$ (Brown and Bark 1971, Bark 1987).

The soil at the Konza Prairie is a silty clay loam (Udic haplustoll) with color ranging from dark gray when dry to almost black when moist. Depth is, on average, $\approx 1 \mathrm{~m}$ to bedrock (Hayes and Seastedt 1987); however, topoedaphic features are particularly important at the Konza due to their complex nature. Konza Prairie is located in the Flint Hills region of northeastern Kansas. Topographic position is believed to be significant because of the juxtaposition of layers of impermeable shale and fractured limestone resulting in a "stair step" appearance, which at any given point may contain a number of different soil types and depths, although all are considered mollisols (Jantz et al. 1975). Consequently, many of the upland slopes and hilltops contain exposed limestone overlaid by a sparse grass canopy.

Konza Prairie is managed as a watershed level fire frequency experiment with replicated watershed units under a variety of mid-April prescribed burning regimes ranging from annual, 2-yr, 4-yr, and 10-yr intervals to long-term unburned sites. Burned watersheds are dominated by grass species and are spatially more uniform than other watershed types. Unburned watersheds have abundant surface litter and may have more non-grass species since succession is not suppressed by fire. Grazed watersheds are likely to have the greatest spatial variability due to selective grazing, trampling, and nutrient input by cattle (Hobbs et al. 1991). Burning of a grazed watershed reduces the landscape to uniform, pre-grazed conditions.

\section{Ground sampling}

Estimates of peak foliar biomass (excluding trees) were obtained between 6 and 20 September from watersheds being studied as a part of the LTER program (e.g., Briggs et al. 1989). The time period from midAugust to mid-September usually represents peak growing season prior to onset of senescence. For each watershed, 20-40 replicate plots of area $0.1 \mathrm{~m}^{2}$ were clipped to bare soil: $10-20$ plots were from a lowland 
TABle 1. Biomass data (in grams per square meter of ground surface) collected in 1990 as part of the Konza Prairie LTER project. Data represent means \pm 1 SE. Watersheds are described in Fig. 2; year of the last burn is in parentheses.

\begin{tabular}{|c|c|c|c|c|c|c|}
\hline \multirow[b]{2}{*}{ Watersheds } & \multicolumn{6}{|c|}{ Landscape component } \\
\hline & Grasses & Forbs & Standing dead & Litter & Total live & Total biomass \\
\hline $\begin{array}{l}20 \mathrm{~A} \\
(1980) \\
20 \mathrm{~B}\end{array}$ & $188.6 \pm 22.6$ & $47.8 \pm 6.9$ & $23.6 \pm 2.8$ & $743.2 \pm 56.5$ & $236.3 \pm 23.5$ & $260.0 \pm 25.9$ \\
\hline $\begin{array}{l}20 \mathrm{~B} \\
1 \mathrm{~A}\end{array}$ & $187.3 \pm 16.7$ & $50.2 \pm 5.25$ & $92.5 \pm 10.4$ & $676.3 \pm 37.9$ & $237.5 \pm 17.4$ & $330.0 \pm 23.55$ \\
\hline $1 \mathrm{C}^{(1990)}$ & $352.8 \pm 23.6$ & $45.9 \pm 5.6$ & $72.0 \pm 5.2$ & $0 \pm 0$ & $399.0 \pm 24.31$ & $470.7 \pm 28.4$ \\
\hline${ }_{1 \mathrm{D}}^{(1990)}$ & $293.0 \pm 21.0$ & $40.6 \pm 4.8$ & $147.7 \pm 8.15$ & $0 \pm 0$ & $333.6 \pm 19.8$ & $481.3 \pm 25.3$ \\
\hline $2 \mathrm{D}$ & $364.3 \pm 29.5$ & $25.0 \pm 3.6$ & $127.3 \pm 8.0$ & $0 \pm 0$ & $389.35 \pm 29.3$ & $516.6 \pm 36.1$ \\
\hline $4 \mathrm{~B}^{(1990)}$ & $244.1 \pm 19.4$ & $23.2 \pm 4.5$ & $128.9 \pm 10.9$ & $0 \pm 0$ & $267.3 \pm 19.1$ & $396.2 \pm 19.9$ \\
\hline $\begin{array}{l}(1987) \\
\mathrm{N} 20 \mathrm{~B} \dagger\end{array}$ & $154.1 \pm 13.6$ & $42.15 \pm 3.9$ & $84.2 \pm 5.8$ & $477.08 \pm 29.3$ & $196.25 \pm 13.0$ & $280.53 \pm 15.6$ \\
\hline $\begin{array}{l}(1980) \\
\text { N1A }\end{array}$ & $197.4 \pm 14.7$ & $44.3 \pm 5.4$ & $75.8 \pm 5.9$ & $577.1 \pm 35.5$ & $241.7 \pm 14.8$ & $317.51 \pm 18.6$ \\
\hline $\begin{array}{c}(1990) \\
\mathrm{N} 1 \mathrm{~B} \dagger\end{array}$ & $186.8 \pm 16.25$ & $45.76 \pm 7.6$ & $150.5 \pm 15.25$ & $0 \pm 0$ & $232.6 \pm 17.2$ & $383.1 \pm 27.5$ \\
\hline $\begin{aligned} &(1990) \\
& \mathrm{N} 4 \mathrm{D} \dagger\end{aligned}$ & $423.05 \pm 31.9$ & $19.9 \pm 4.0$ & $209.1 \pm 11.97$ & $0 \pm 0$ & $442.9 \pm 30.9$ & $652.0 \pm 38.6$ \\
\hline $\begin{array}{l}(1988) \\
\mathrm{N} 20 \mathrm{~A} \dagger\end{array}$ & $234.55 \pm 17.0$ & $46.95 \pm 4.3$ & $88.85 \pm 8.4$ & $317.9 \pm 19.0$ & $281.5 \pm 16.35$ & $370.4 \pm 20.7$ \\
\hline (1990) & $137.3 \pm 13.0$ & $51.1 \pm 7.6$ & $105.3 \pm 9.35$ & $0 \pm 0$ & $188.4 \pm 14.0$ & $293.7 \pm 19.1$ \\
\hline
\end{tabular}

$\dagger$ Grazed after 1990 .

$\ddagger$ Total live represents grasses plus forbs; total biomass represents total live plus standing dead.

area and 10-20 were from an upland area. All clippings were hand-sorted into four categories: graminoids (grasses and sedges), forbs (herbaceous dicots with, occasionally, a small woody plant component), current dead (standing litter from current growing season), and litter (litter layer from previous growing seasons). For watershed level estimates of these parameters, data from all samples were combined and averaged (equally weighted for uplands and lowlands, although the actual watershed portion may have been different). The graminoids dominate the total live green biomass and are referred to as the "green" component throughout this paper. We also consider categories of total live (grasses and forbs) and total biomass (total live and current dead; Table 1).

\section{Image processing and analysis}

Imagery from the U.S. National Aeronautics and Space Administration's (NASA) Airborne Visible/Infrared Imaging Spectrometer (AVIRIS) was acquired over the Konza Prairie Research Natural Area on 31 August 1990 at 1730 Greenwich Mean Time (1130 local time). AVIRIS measures the total upwelling radiance from 400 to $2500 \mathrm{~nm}$ through 224 channels and is flown at an altitude of $20 \mathrm{~km}$ for a nominal spatial resolution of $20 \mathrm{~m}$ and a swath width of $11 \mathrm{~km}$ (Vane et al. 1993). Observed radiance values were reduced to apparent surface reflectance using a solar and atmospheric model (ATmospheric REMoval Model [ATREM]; Gao et al. 1993).

Because instrumental noise may significantly affect the directions of the eigenvectors from a principal component analysis (PCA) of remotely sensed data (used in spectral mixture analysis), a noise reduction method (the Minimum Noise Fraction [MNF] transform; Green et al. 1988) was applied to the AVIRIS imagery prior to the PCA. The MNF transform scales the data so that noise is isotropic with unit variance in all directions; under this condition, noise is not a factor in determining directions of maximum variance (i.e., the PCA eigenvectors). After a PCA, component images of the MNFtransformed data show decreasing quality with increasing component number. In particular, any component image representing a direction of unit variance consists entirely of noise. Noisier component images can be removed from the transformed data and the data transformed back into the space of the original AVIRIS bands to obtain a noise-reduced data set.

Computation of NDVI and linear spectral mixture analysis (LSMA) were both performed on the ATREMcorrected and noise-reduced AVIRIS imagery. The NDVI image was constructed using the equation NDVI $=(\mathrm{NIR}-\mathrm{R}) /(\mathrm{NIR}+\mathrm{R})$, where $\mathrm{R}$ is the red reflectance at band $29(675 \mathrm{~nm})$ and NIR the reflectance at band $50(844 \mathrm{~nm})$.

LSMA of the Konza image interpreted each spectrum of the AVIRIS image as a mixture or linear combination of a finite number of endmembers with non-negative abundances summing to 1 . For each endmember, an image was constructed consisting of the abundances or fractions of that endmember in the pixels of the AVIRIS image. 
The endmembers used to unmix the AVIRIS image were derived from the spectra of all pixels in the 12 watersheds with a manual endmember selection method (MESM; for a complete description see Bateson and Curtiss 1996). The MESM first computes the mean spectrum of all spectra used in the selection. A computer display allows the user to interactively select endmembers by adding to this mean multiples of the PCA eigenvectors that account for most of the variance in the spectra. Therefore, because the endmembers are derived from the variance structure of the data, the shape of each selected endmember can be influenced not only by the spectral signatures of specific ground materials (e.g., vegetation, soil, rock, and nonphotosynthetic vegetation [NPV]) but also by other factors affecting the signal received by the sensor (e.g., multiple scattering of radiation between surface materials such as vegetation, soil, and bark; atmospheric scattering; shading; and illumination geometry). In this study, we chose the MESM over library-based methods of endmember selection (e.g., Smith et al. 1990) because the MESM does not require access to a large spectral library or, alternatively, extensive field work to assemble a collection of field endmembers adequately representing the radiative processes and factors affecting the spectral data.

Many unmixing studies have used three to five endmembers (e.g., shade, soil, green vegetation, often NPV, and perhaps rock) to analyze remotely sensed scenes (Gamon et al. 1993, Roberts et al. 1993, Smith et al. 1994, Adams et al. 1995). In that mathematical framework, the significant spectral influences mentioned may be relegated to the residuals of the model. Such a predetermined model is inadequate for our goal to discern remotely sensed factors indicative of burn and grazing management practices, since some of those factors may be lost to the residuals and hence would not be identifiable in terms of the endmembers. In fact, we include in this paper a principal components regression that strongly suggests that six eigenvectors and, hence, seven endmembers (Bateson and Curtiss 1996) are needed to obtain an endmember the fractions of which are significantly correlated with graminoid biomass measured in the field.

\section{Statistical analysis}

To determine if the field biomass values discriminated between the treatments, $t$ tests were performed. Also, endmember fractions and NDVI values for the pixels of each of the watersheds were extracted from the corresponding images. Averages for each watershed were computed and regressed against corresponding ground values. Regression analyses and scatterplots were accomplished with the Interactive Data Language (IDL; RSI, Boulder, Colorado).

Principal component regressions were performed for subsets of the eigenvectors to examine the hypothesis that seven endmembers are needed to discern remotely sensed indicators of grazing and burning management practices. For this analysis, the average spectrum of each watershed was computed and corrected with the mean of all spectra used in the endmember selection. Eigenvector scores were next determined for each mean-corrected watershed spectrum. For each selection of endmembers and each endmember in the selection, there is a linear equation for computing concentrations from the eigenvector scores. Hence, a principal component linear regression involving a subset of the eigenvectors and the field graminoid biomass values produces an upper bound on the correlation coefficients (relating abundance fractions and field graminoid biomass values) obtainable with any set of endmembers constructed from the eigenvectors in the subset. Regressions between eigenvector scores and field values were performed with IDL.

In order to assess quantitatively the ability of endmember abundances and the NDVI to distinguish between burn and grazing treatments on a larger subset of the image than the 12 watersheds (only two of these watersheds were grazed in 1990), we performed several ANOVAs on an expanded subset of 37 watersheds with known burning and grazing histories (Benning 1993). Of these watersheds, five were grazed by bison at the time of the overflight. The two factors of grazing and burning were considered in the ANOVAs. The grazing factor has two levels: grazed and ungrazed. The burn factor can have four levels based on the burning treatment for the year of the overflight (1990) and on the time period between burnings. These levels are (1) UB: unburned in $1990(n=22)$; (2) B1: burned in 1990 and $1989(n=7)$; (3) B2: burned in 1990 and 1988 ( $n$ $=3)$; and (4) B4: burned in 1990 and $1986(n=5)$.

A two-way classification with all levels of each factor leaves too few samples in some of the categories (e.g., no watershed is in the grazed B2 category). To minimize this imbalance, we performed two ANOVAs: (1) a one-way ANOVA with the four-level burn factor and (2) a two-way ANOVA with the two-level grazing factor and a two-level burn factor distinguishing between burned and unburned watersheds. The last design also included interactions between burning and grazing treatments. ANOVA tests were conducted with the statistical package $\mathrm{S}+$ (MathSci, Seattle, Washington).

\section{RESUlts}

\section{MNF transform}

Fig. 3 shows the first, sixth, and seventh eigenimages of a subset of the forward MNF transformed Konza image. This subset includes our study sites. Since there is spatial information within the Konza research area in the sixth eigenimage but not in the seventh, we removed all but the first six eigenbands from the forward MNF transformed cube and applied the inverse MNF transform to obtain relatively noise-free imagery. This 
imagery has six dimensions and, hence, by theory (Bateson and Curtiss 1996), seven endmembers.

\section{Field data}

Initial $t$ tests on all the field data, including the 12 sampled watersheds, resulted in insignificant relationships for all but litter and current dead categories. Due to the lack of unburned, grazed watersheds, the grazing treatment was underrepresented and a second set of $t$ tests was performed with grazed watersheds removed. Among all ungrazed watersheds, every category of biomass was found to significantly separate among burn treatments (Table 2).

\section{NDVI image}

Topography of the Konza Prairie, particularly as it affects water and nutrient availability and, hence, chlorophyll concentrations (Schimel et al. 1991), appears to drive the NDVI values (Fig. 4a). High NDVI values mainly occur over the vegetation along King's Creek (e.g., in Fig. 4a compare watersheds K4A with K4B, which are labeled in Fig. 2), Shane's Creek (see watersheds SA and SB), and in the lowlands, whereas the ridge tops with low NDVI values are a darker grey. Differentiation between burning treatments of the watersheds is muted; e.g., there are only subtle changes in image values along the alternating sequence of burned and unburned watersheds in the lower left corner of the research area (watersheds 20A, 1A, 2A, 1B, 4C, and 4D). Nevertheless, a two-way ANOVA (Table 3 ) performed on the enlarged set of 37 watersheds revealed that NDVI values detected significant $(P=$ 0.00002 ) differences between burned and unburned watersheds in that set. No differences were detected between grazed and ungrazed watersheds $(P=0.09)$. However, there is a significant interaction $(P=0.02)$ between grazing and burning, which may be seen in Table 4, where there is a detectable difference between predicted mean NDVI values for burned and unburned watersheds that have not been grazed and almost no difference for burned and unburned treatments on grazed watersheds; that is, the difference between burned and unburned treatments is not as distinct on grazed watersheds.

NDVI did not have a significant correlation with graminoid biomass $(R=0.51, P=0.088)$ in the 12 watersheds comprising the study sites (Table 5, Fig. 5). The lack of correlation between NDVI and graminoid biomass may be explained by the presence of trees, particularly in the watersheds that are crossed by branches of King's Creek. At a scale of $20 \mathrm{~m}$, these trees affect the signal received by the sensor and, thus, the computation of NDVI. However, they are not included in the sampling scheme for the ground measurements.

\section{Endmembers}

The seven endmembers constructed with the MESM are shown in Fig. 6 and identified as NPV, green veg- etation 1 (GV1), shade, soil, rock, green vegetation 2 $(\mathrm{GV} 2)$, and green vegetation 3 (GV3), in order of selection.

\section{Three vegetation endmembers}

The contribution of vegetation to the spectral signal recorded by the AVIRIS instrument was attributed to varying abundances of three vegetation endmembers. The first of these endmembers, GV1, produced a fraction image (Fig. 4b) similar to the NDVI image in that it very sharply emphasizes topography with high fractional abundances in the lowlands, which have tall grasses, shrubs, and occasional trees, and in the riparian forests following Shane's and King's creeks. The ridge tops have smaller GV1 fractions following the sparser production in these drier areas.

In addition to following topography, GV1's fraction image, unlike the NDVI image, clearly separates fire treatments. For example, note the strong delineation of the sequence of watersheds 20A, 1A, 2A, 1B, 4C, and $4 \mathrm{D}$ along the lower left boundary of the research area in GV1's fraction image as compared to the NDVI image. Particularly noticeable is the distinct boundary between unburned watershed $4 \mathrm{~B}$ and burned watershed $1 \mathrm{~B}$ in the GV1 image. This boundary is faint in the NDVI image. Compared to GV1 fractions, the NDVI overestimated vegetation in the unburned watershed $4 \mathrm{~B}$, perhaps because of the bright litter background.

In both a one-way and two-way ANOVA (Tables 3 and 6) of the 37 watersheds, the GV1 fractions differentiated very significantly $(P=0.0000001)$ between burned and unburned watersheds, although $t$ tests did not reveal significant differences between burning levels (annual, 2-yr, 4-yr, unburned). In the two-way ANOVA, GV1 did not significantly $(F=2.16, P=0.15)$ separate grazed from ungrazed treatments. Moreover, GV1 fractions were not significantly correlated with ground measurements of graminoid biomass $(R=0.31$, $P=0.33$, in Table 5) collected in all 12 watersheds. As with NDVI, the poor regression is probably due to GV1's sensitivity to trees, which are not included in the ground sampling.

The GV2 fraction image is also dominated by topography and the riparian vegetation. GV2 has a negative correlation with ground graminoid biomass (Table 5 ) and does not distinguish between burn treatments in either one- and two-way ANOVA (Tables 3 and 6). However, it separates the grazing treatments very well $(P=0.0009$ in Table 3$)$, grazed watersheds having higher GV2 values than those in ungrazed watersheds (see Table 4). If we add together the GV1 and GV2 fraction images, we obtain an image (Fig. 7a) more similar to the NDVI image than either the GV1 or GV2 image alone. In this image, topography is emphasized and detection of burn history is faint.

The third vegetation endmember (GV3) has the highest correlation with the graminoid biomass $(R=0.69$, $P=0.01$ in Table 5 and Fig. 5) and surpasses the GV2 


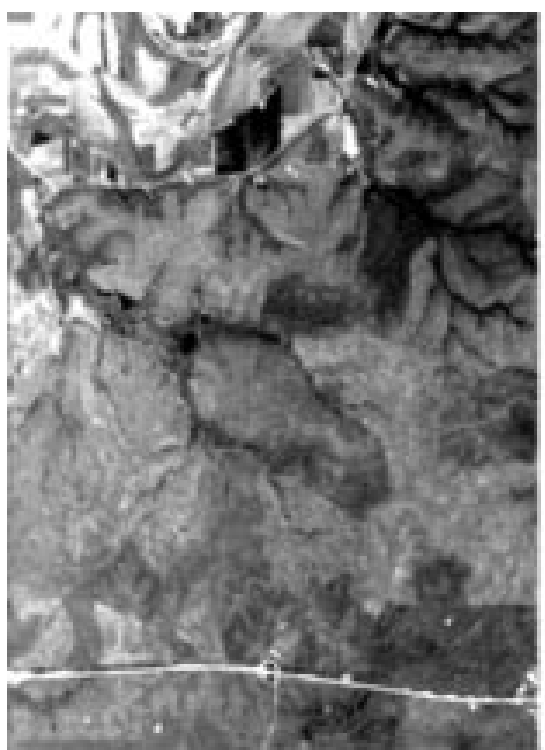

(a)

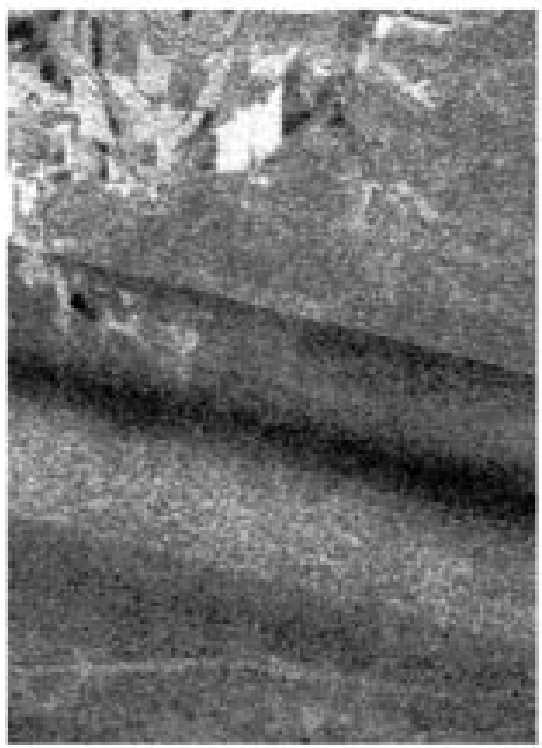

(c)

in its differentiation of grazing treatments $(P=$ 0.00005 in Table 3). Unlike GV2, GV3 fractions are higher in ungrazed than in grazed watersheds (as in N20A, N1A, N2A, N4c in the middle left portion of the image in Fig. 4d). Burned treatments are not separated by GV3 (Table 3). Note that unlike the GV1 fraction image, the long-term unburned watersheds $20 \mathrm{~B}$ and 20D are not distinguishable from their neighbors in the GV3 image.

The best detection of grasses in this AVIRIS image was achieved with the sum of GV1 and GV3 fractions (Fig. 7b). This is reflected in the correlation between GV1 plus GV3 and graminoid biomass, $(R=0.74, P$

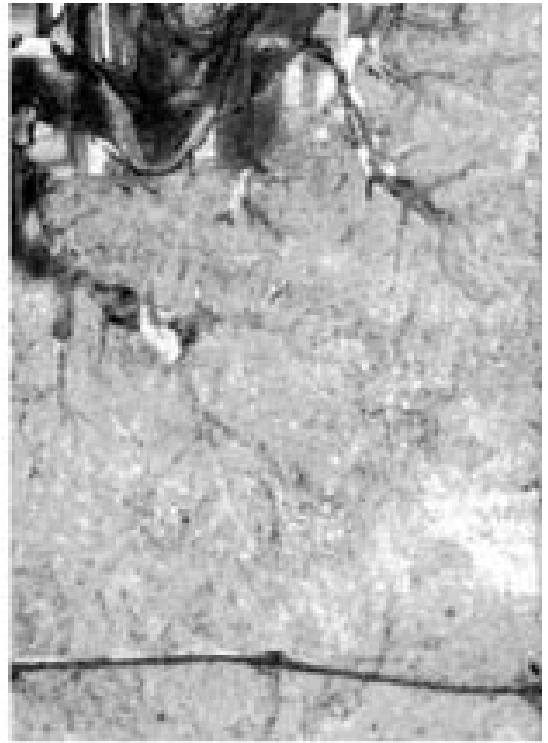

(b)

Fig. 3. The (a) first, (b) sixth, and (c) seventh component images from the forward Minimum Noise Fraction (MNF) transformed cube. Since image quality decreases with increasing component number, noise was removed from the data by discarding all but the first six images.
TABLE 2. Results of $t$ test, including probabilities (Pr), comparing averages for field biomass categories on unburned and burned watersheds. Only the 10 ungrazed watersheds of Table 1 are considered; $t$ tests are two-sided with assumption of equal variances and $\mathrm{df}=8$ in all cases. Negative values of $t$ occur when the average of burned watersheds exceeds average of unburned watersheds.

\begin{tabular}{crl}
\hline \hline Landscape component & $t$ value & $\operatorname{Pr}(t)$ \\
\hline Grass & -4.29 & 0.0027 \\
Forbs & 2.87 & 0.021 \\
Current dead & -2.52 & 0.036 \\
Litter & 7.43 & 0.0001 \\
Total live & -3.85 & 0.0049 \\
Biomass & -4.15 & 0.0032 \\
\hline
\end{tabular}




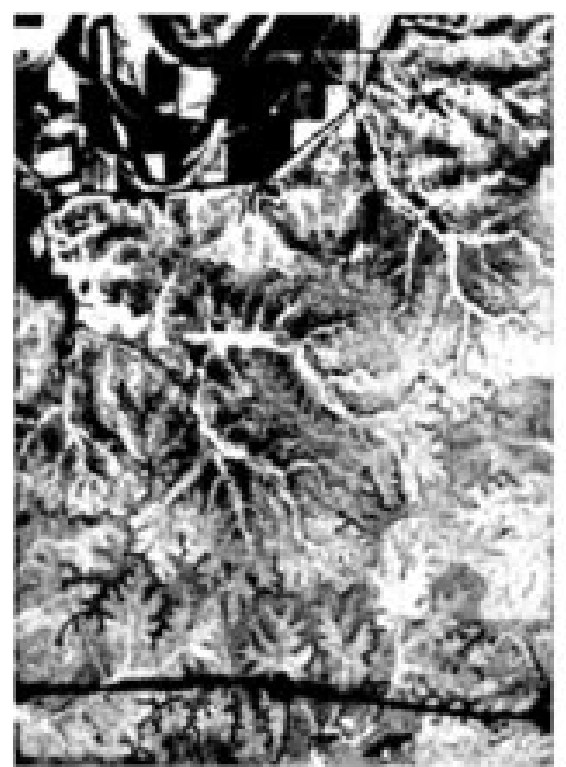

(a)

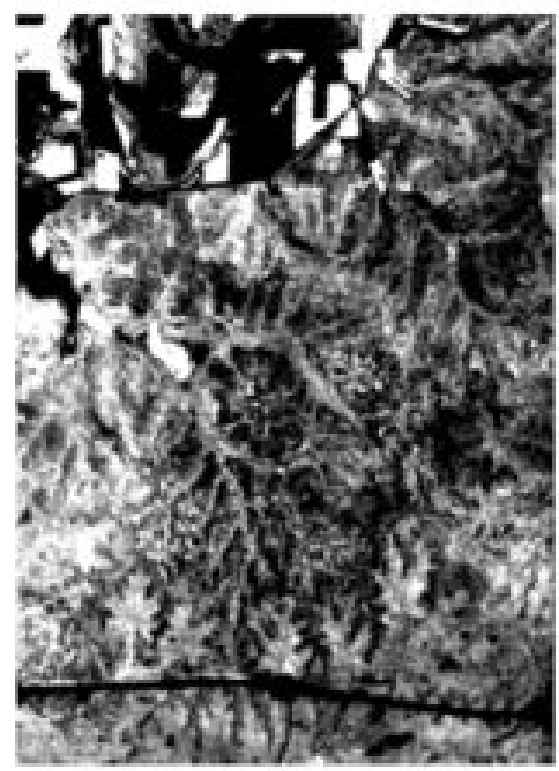

(c)

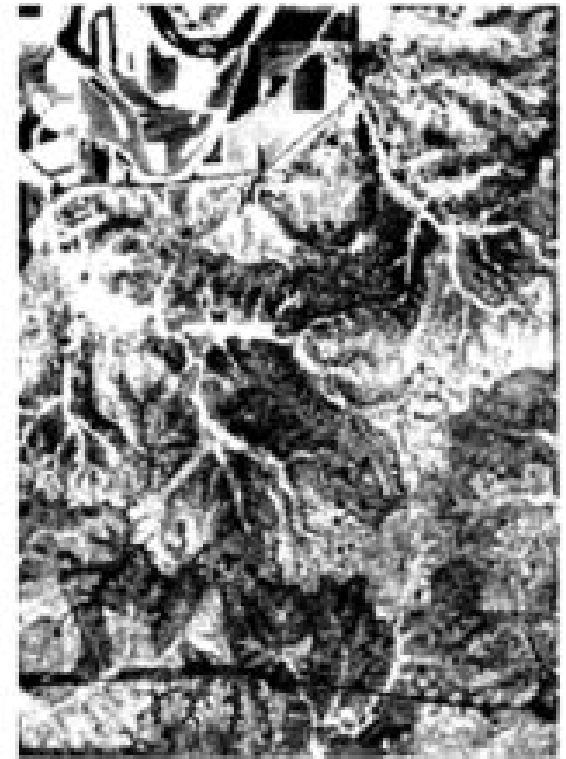

(b)

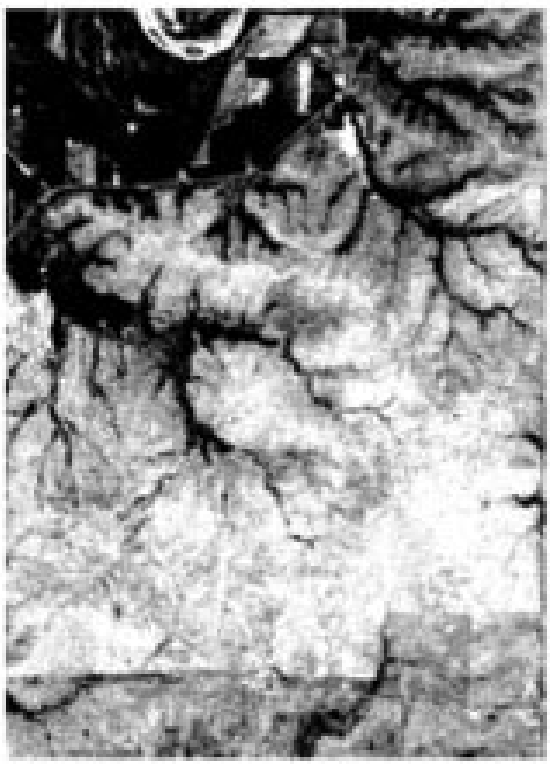

(d)

FIG. 4. NDVI and three Green Vegetation (GV) fractional abundance images: (a) NDVI, (b) GV1 (LAI), (c) GV2 (greenness), and (d) GV3 (grass cover). Abundance fractions and NDVI values are high in bright areas of the images.

$=0.01)$ in Table 5 and Fig. 5. In a two-way ANOVA (Table 3 ), the sum was highly significant in detecting burn treatments $(F=37.65, P=0.000006)$ and grazing patterns $(F=15.34, P=0.0004)$. There were also significant interactions $(F=13.80, P=0.0007)$ between the two treatments. The GV1 plus GV3 fraction combines GV1's discrimination of burned from unburned watersheds with GV3's response to grass cover. Note that the trees in riparian forests are not emphasized in the image itself and most grazed and unburned watersheds are clearly darker than burned watersheds, with the exception of the cattle grazed watersheds on the right hand side.

\section{Nonphotosynthetic vegetation}

Of all the images derived in the analysis (NDVI included), the NPV image (Fig. 8a) shows the most striking delineation of the watersheds. The NPV endmember is responding to the sharp contrast between the presence of litter in the unburned watersheds and its absence in the burned watersheds. For example, notice in the NPV image the clear discrimination of burned 
TABLE 3. ANOVA results including probabilities $(\mathrm{Pr})$, for the two-factor model (Burn and Grazing) with interactions. Burn has two levels: burned and unburned. Grazing also has two levels: grazed and ungrazed.

\begin{tabular}{|c|c|c|c|}
\hline Image variable & $\mathrm{df}$ & $F$ value & $\operatorname{Pr}(F)$ \\
\hline \multicolumn{4}{|l|}{ NDVI } \\
\hline Burn & 1 & 32.42 & 0.0000238 \\
\hline Grazing & 1 & 3.04 & 0.09 \\
\hline Burn : Grazing & 1 & 6.39 & 0.02 \\
\hline \multicolumn{4}{|l|}{ GV1 } \\
\hline Burn & 1 & 111.43 & 0.0000001 \\
\hline Grazing & 1 & 2.16 & 0.15 \\
\hline Burn : Grazing & 1 & 5.90 & 0.02 \\
\hline \multicolumn{4}{|l|}{ GV2 } \\
\hline Burn & 1 & 3.42 & 0.07 \\
\hline Grazing & 1 & 13.25 & 0.0009 \\
\hline Burn : Grazing & 1 & 2.73 & 0.10 \\
\hline \multicolumn{4}{|l|}{ GV3 } \\
\hline Burn & 1 & 0.56 & 0.46 \\
\hline Grazing & 1 & 21.96 & 0.000046 \\
\hline Burn : Grazing & 1 & 6.17 & 0.018 \\
\hline \multicolumn{4}{|l|}{$\mathrm{GV} 1+\mathrm{GV} 3$} \\
\hline Burn & 1 & 37.65 & 0.000006 \\
\hline Grazing & 1 & 15.34 & 0.0004 \\
\hline Burn : Grazing & 1 & 13.80 & 0.0007 \\
\hline \multicolumn{4}{|l|}{ NPV } \\
\hline Burn & 1 & 104.88 & 0.0000001 \\
\hline Grazing & 1 & 5.01 & 0.03 \\
\hline Burn : Grazing & 1 & 6.94 & 0.01 \\
\hline \multicolumn{4}{|l|}{ Soil } \\
\hline Burn & 1 & 1.15 & 0.29 \\
\hline Grazing & 1 & 14.88 & 0.0005 \\
\hline Burn : Grazing & 1 & 6.69 & 0.014 \\
\hline
\end{tabular}

Note: Error df $=33$.

and unburned watersheds along the lower left boundary of the research area and the clear separation between the burned and unburned areas that are separated by a fence in watershed K20A. Moreover, the bright strips flanking Interstate 70 consist of mowed grasses that have dried by late August (T. R. Seastedt, personal communication). The NPV fractions have highly significant correlations $(R=0.89, P=0.0001$ in Table 5 and Fig. 5) with the sum of field litter and standing dead. In a two-way ANOVA, the fractions produced a very significant discrimination between burned and unburned watersheds $(F=105, P=0.0000001$ in Table $3)$.

\section{Soil}

The soil image (Fig. 8b) shows the highest concentration of soil along some of the ridge tops and around the creek, particularly in the grazed watersheds. Note, for example, high soil concentrations in watersheds N20A and N1A. Cattle and bison paths to the water likely account for the exposed soil around the creek. In a two-way ANOVA, soil discriminated significantly $(F=14.88, P=0.0005$ in Table 3$)$ between grazed and ungrazed watersheds.

\section{Rock}

The rock fractional abundance image (Fig. 8c) highlights some ridge tops and the central plateau above King's creek. Ridges frequently have shallow rocky soils and occasionally Permian limestone and shale strata are exposed on steep-sided hills. Two rock outcroppings may be seen in the lower right hand corner outside of the research area. Overall, however, this endmember does not differentiate between burning and grazing treatments. Its spatial distribution in the image is fairly uniform over the research area, consistent with the common geology across watershed units (see Jantz et al. 1975).

\section{Shade}

The shade endmember fraction image (Fig. 8d) picks up shade around the trees in riparian forests. It highlights the unburned watersheds in the lower half of the research area, probably because of shadowing in the complex of litter and green grass.

\section{Color composite image}

The color composite image in Fig. 9 displays the relation between grass, soil, and litter fractions in the Konza Prairie. Subpixel mixing is easier to discern in this image than in the gray scale fraction images. Subpixel variation in vegetation and soil fractions is particularly evident in some of the grazed watersheds such as N20A and N1A. The unburned watersheds (20A and $2 \mathrm{~A}$, for example) are mixtures of litter and vegetation.

\section{Eigenvector analysis}

Table 7 shows the correlation coefficients and significances obtained when principal component regressions were performed to test the sensitivity of eigenvector directions to the 12 graminoid biomass values (see Methods for full description). Among the six eigenvectors used in the selection of endmembers and analysis, the sixth eigenvector was the most sensitive $(R=-0.67, P=0.02)$ to changes in biomass. High biomass values were associated with watersheds whose average spectra have large negative scores in the di-

TABLE 4. Table of predicted mean values for NDVI and each endmember fraction in watersheds that have been: burned and ungrazed, unburned and ungrazed, burned and grazed, unburned and grazed. These values are the fitted values from the two-way ANOVA in Table 3.

\begin{tabular}{lcccc}
\hline \hline & \multicolumn{4}{c}{ Treatment } \\
\cline { 2 - 5 } Image variable & $\begin{array}{c}\text { Burned, } \\
\text { ungrazed }\end{array}$ & $\begin{array}{c}\text { Unburned, } \\
\text { ungrazed }\end{array}$ & $\begin{array}{c}\text { Burned, } \\
\text { grazed }\end{array}$ & $\begin{array}{c}\text { Unburned, } \\
\text { grazed }\end{array}$ \\
\hline NDVI & 0.73 & 0.69 & 0.70 & 0.70 \\
GV1 & 0.126 & 0.091 & 0.123 & 0.11 \\
GV2 & 0.10 & 0.09 & 0.12 & 0.14 \\
GV3 & 0.42 & 0.41 & 0.36 & 0.39 \\
GV1 + GV3 & 0.55 & 0.50 & 0.48 & 0.50 \\
NPV & 0.058 & 0.094 & 0.058 & 0.069 \\
Soil & 0.09 & 0.09 & 0.13 & 0.10 \\
\hline
\end{tabular}


TABLE 5. Pearson's correlation coefficient ( $R$ values) measuring the relationship between field biomass measurements and appropriate endmember fractions and NDVI. Significance of each $R$ value appears in parentheses.

\begin{tabular}{|c|c|c|c|c|c|c|c|}
\hline \multirow[b]{2}{*}{$\begin{array}{c}\text { Image } \\
\text { variable }\end{array}$} & \multicolumn{7}{|c|}{ Landscape component } \\
\hline & $\begin{array}{c}\text { Green } \\
\text { vegetation }\end{array}$ & Forbs & Current dead & Litter & Total live & Biomass & $\begin{array}{l}\text { Litter and } \\
\text { current dead }\end{array}$ \\
\hline NDVI & $\begin{array}{c}0.51 \\
(0.088)\end{array}$ & $\begin{array}{l}-0.70 \\
(0.011)\end{array}$ & $\begin{array}{c}0.27 \\
(0.39)\end{array}$ & $\begin{array}{c}-0.45 \\
(0.14)\end{array}$ & $\begin{array}{c}0.47 \\
(0.13)\end{array}$ & $\begin{array}{c}0.45 \\
(0.14)\end{array}$ & $\begin{array}{c}-0.45 \\
(0.14)\end{array}$ \\
\hline GV1 & $\begin{array}{c}0.31 \\
(0.33)\end{array}$ & $\begin{array}{c}-0.27 \\
(0.39)\end{array}$ & $\begin{array}{c}0.21 \\
(0.50)\end{array}$ & $\begin{array}{c}-0.64 \\
(0.02)\end{array}$ & $\begin{array}{c}0.30 \\
(0.34)\end{array}$ & $\begin{array}{c}0.31 \\
(0.33)\end{array}$ & $\begin{array}{c}-0.68 \\
(0.02)\end{array}$ \\
\hline GV2 & $\begin{array}{c}-0.39 \\
(0.21)\end{array}$ & $\begin{array}{c}0.35 \\
(0.27)\end{array}$ & $\begin{array}{c}-0.45 \\
(0.14)\end{array}$ & $\begin{array}{c}0.05 \\
(0.88)\end{array}$ & $\begin{array}{c}-0.37 \\
(0.23)\end{array}$ & $\begin{array}{c}-0.46 \\
(0.13)\end{array}$ & $\begin{array}{c}-0.02 \\
(0.94)\end{array}$ \\
\hline GV3 & $\begin{array}{c}0.69 \\
(0.01)\end{array}$ & $\begin{array}{c}-0.60 \\
(0.04)\end{array}$ & $\begin{array}{c}0.10 \\
(0.76)\end{array}$ & $\begin{array}{c}-0.17 \\
(0.61)\end{array}$ & $\begin{array}{c}0.67 \\
(0.02)\end{array}$ & $\begin{array}{c}0.53 \\
(0.08)\end{array}$ & $\begin{array}{c}-0.17 \\
(0.60)\end{array}$ \\
\hline $\mathrm{GV} 1+\mathrm{GV} 3$ & $\begin{array}{c}0.74 \\
(0.01)\end{array}$ & $\begin{array}{c}-0.64 \\
(0.02)\end{array}$ & $\begin{array}{c}0.19 \\
(0.55)\end{array}$ & $\begin{array}{l}-0.46 \\
(0.13)\end{array}$ & $\begin{array}{c}0.71 \\
(0.01)\end{array}$ & $\begin{array}{c}0.60 \\
(0.04)\end{array}$ & $\begin{array}{c}-0.48 \\
(0.11)\end{array}$ \\
\hline NPV & $\begin{array}{c}-0.42 \\
(0.17)\end{array}$ & $\begin{array}{c}0.46 \\
(0.13)\end{array}$ & $\begin{array}{c}-0.40 \\
(0.20)\end{array}$ & $\begin{array}{c}0.86 \\
(0.00)\end{array}$ & $\begin{array}{c}-0.40 \\
(0.20)\end{array}$ & $\begin{array}{l}-0.46 \\
(0.14)\end{array}$ & $\begin{array}{c}0.89 \\
(0.00)\end{array}$ \\
\hline
\end{tabular}

rection of the sixth eigenvector. Note from Table 8 that $\mathrm{GV} 3$ is the only vegetation endmember with a negative score for the sixth eigenvector.

The correlation coefficient of 0.68 obtained with the scores of the first four eigenvectors in Table 7 implies that no matter which four endmembers are selected from the space spanned by those eigenvectors, a multiple regression of their fractions against field grass biomass values would never produce a correlation coefficient exceeding 0.68. Moreover, it may not be possible to find meaningful endmembers whose fractions attain this limit. In fact, because no eigenvector had scores significantly correlated with grass in this regression, we cannot reject the hypothesis that a cor- relation coefficient of 0.68 is due to chance in a regression that uses four variables to predict 12 samples. If we only used the last two eigenvectors for endmember selection and unmixing, that upper limit on the correlation coefficient is increased to 0.90 with both sets of eigenvector scores significant in the regression.

These regression results suggest that the last two eigenvectors are needed to find reasonable endmembers with fractions adequately correlated with grass biomass. To prevent the loss of spectral information indicative of grazing and burning treatments, our analysis should include not only the eigenvectors tracking grasses (the fifth and sixth eigenvectors) but also the first four eigenvectors, because they individually account
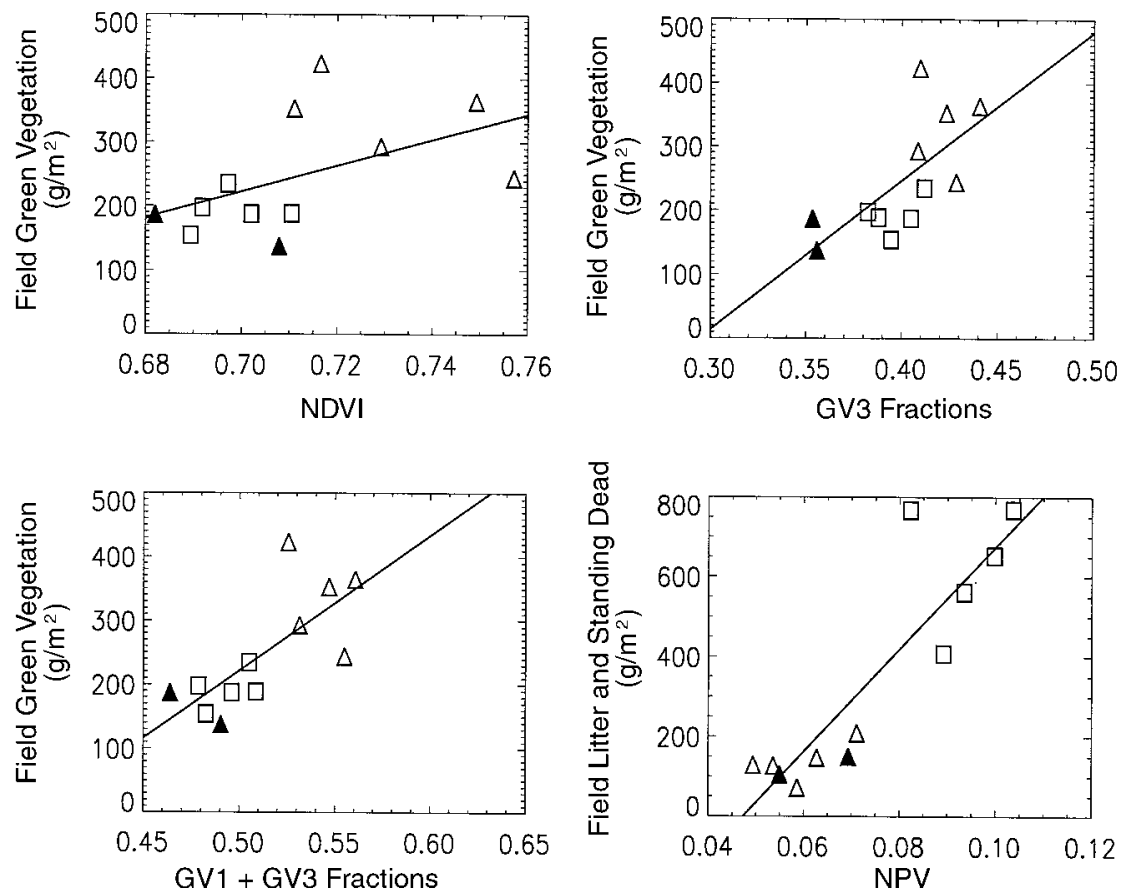

FIG. 5. Scatter plots and regression lines for appropriate ground measurements vs. NDVI and selected endmember fractions averaged over each of 12 watersheds. Unburned $=\square$, burned $=\triangle$; grazed watersheds have filled symbols. 

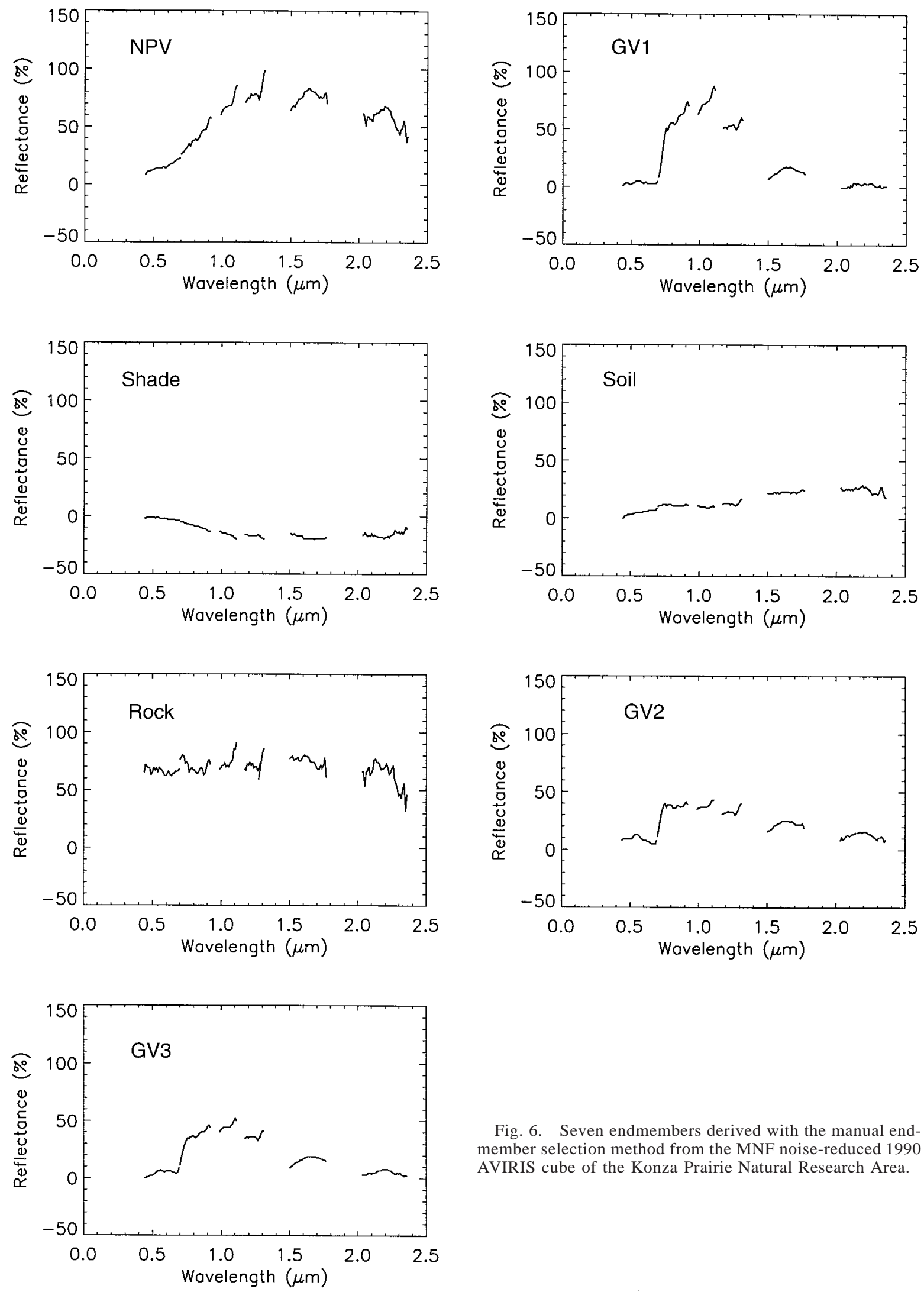

Fig. 6. Seven endmembers derived with the manual endmember selection method from the MNF noise-reduced 1990 AVIRIS cube of the Konza Prairie Natural Research Area. 
TABLE 6. ANOVA results, including probabilities (Pr), for the one-factor model (Burn), where Burn has four levels. ( $\mathrm{df}=3$ in all cases.)

\begin{tabular}{lrl}
\hline \hline Image variable & $F$ value & \multicolumn{1}{c}{$\operatorname{Pr}(F)$} \\
\hline NDVI & 9.87 & 0.00009 \\
GV1 & 31.38 & 0.000001 \\
GV2 & 1.16 & 0.34 \\
GV3 & 0.19 & 0.90 \\
GV1 + GV3 & 7.18 & 0.0008 \\
NPV & 26.12 & 0.000001 \\
Soil & 0.47 & 0.71 \\
\hline
\end{tabular}

Note: Error $\mathrm{df}=33$

for more of the variance in the data than either the fifth or sixth eigenvector. Hence, although many unmixing studies have used only three to five endmembers (Gamon et al. 1993, Roberts et al. 1993, Smith et al. 1994, Adams et al. 1995), six dimensions and, thus, seven endmembers were needed to analyze responses to grazing and burning in the Konza research area at the time of the 1990 August overflight.

\section{DISCUSSION}

As expected, burning significantly changed the distribution of ground materials from the undisturbed state as illustrated by significant separation of burn treatments by all categories of ground biomass measurements on 10 watersheds. (Two burned, grazed watersheds were excluded because field values were not available for any unburned, grazed watersheds.) With litter removal, graminoids produced significantly more mass and stature in response to increased PAR and warmer soils in burned watersheds (Knapp 1984, 1985,

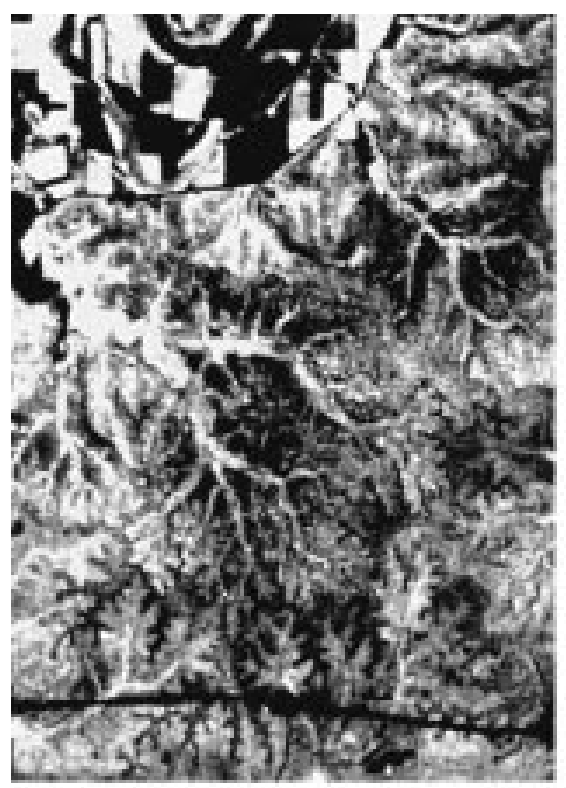

(a)
Knapp and Seastedt 1986). Depending on the burn frequency, nitrogen availability may also have increased (Ojima et al. 1994). Fire enhanced growth so that current standing dead biomass on recently burned watersheds exceeded that on unburned (Table 1). In contrast, $\mathrm{C}_{3}$ forbs and grasses were more abundant in unburned areas due in part to their early establishment in the absence of burning.

NDVI was unresponsive to fluctuations in biomass across burned and unburned watersheds, shown by its correlation with measured graminoid biomass (Table $5)$. Because the NDVI has generally performed better in relationships with FPAR than with biomass (Hatfield et al. 1984, Sellers 1985, 1987, Asrar et al. 1986, Bartlett et al. 1990), the NDVI's insignificant relationship with total aboveground biomass values was expected. Even the distinction of green biomass did not significantly improve the relationships, as it did in a field study reported by Gamon et al. (1995), possibly because the mixed landscape composition at the pixel scale has a far stronger influence than at the canopy scale measured in ground studies. Alternatively, the presence of trees in several of the watersheds inflate NDVI values and, because they were not included in ground estimates of biomass, disturb the relationship with the grass.

Although NDVI does not track biomass changes in the restricted set of 12 watersheds, the ANOVA indicates a significant sensitivity to other factors differentiating burned from unburned treatments. However, GV1 has a much stronger discrimination of burn treatments, possibly because NDVI responds to a variety

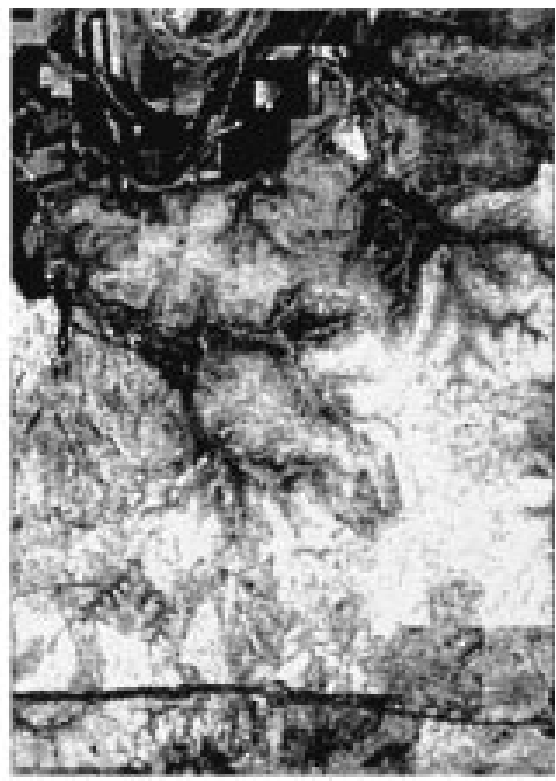

(b)

FIG. 7. Images constructed from endmember abundances and identified with landscape components: (a) GV1 plus GV2 (note highlighting of trees in riparian areas), and (b) GV1 plus GV3 (grass biomass). 


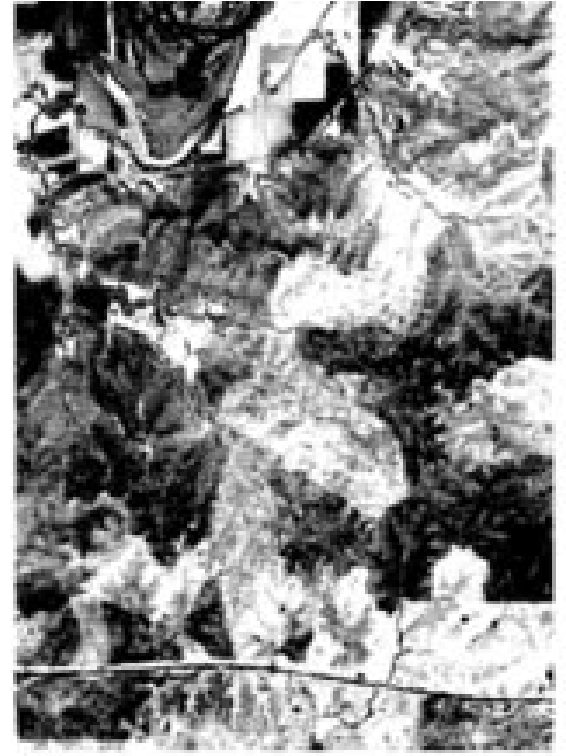

(a)

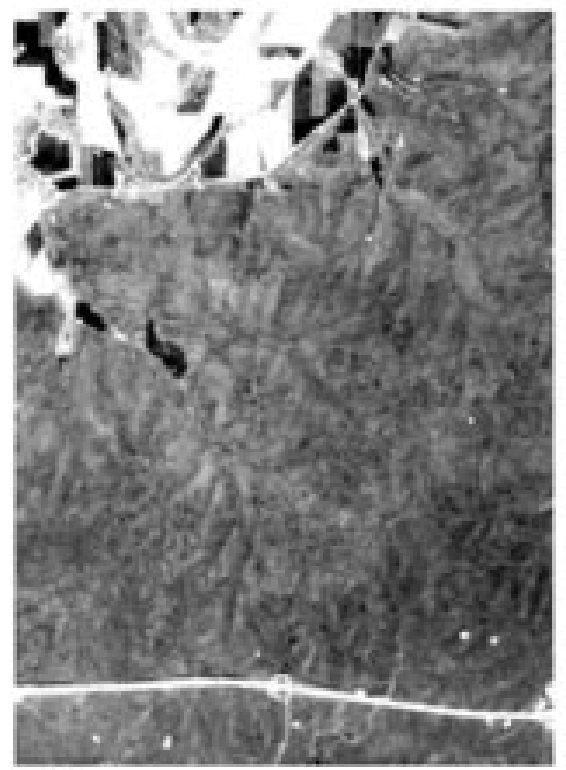

(c)

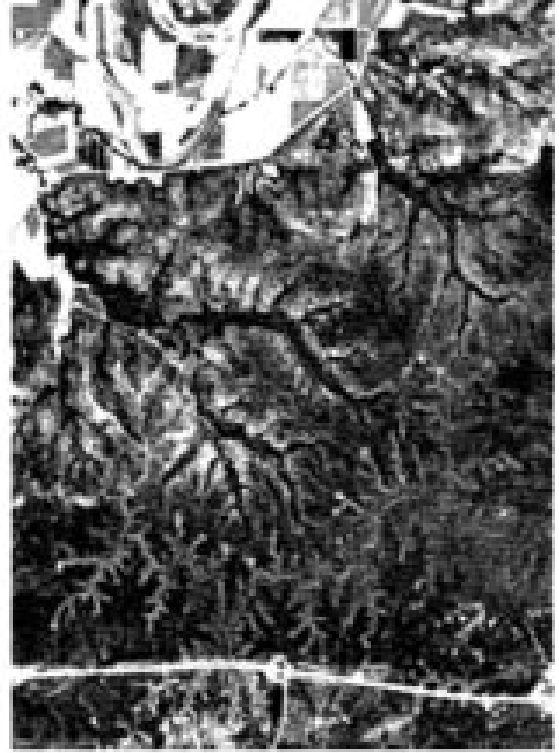

(b)

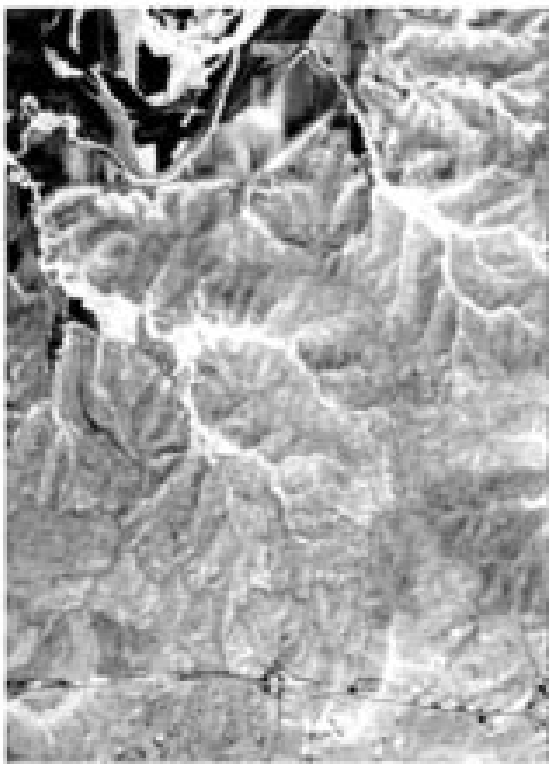

(d)

FIG. 8. Background fractional abundance images: (a) nonphotosynthetic vegetation (NPV), (b) soil, (c) rock, and (d) shade.

of factors such as LAI, chlorophyll concentrations, and FPAR and these factors may not covary positively with each other across burning treatments. The NDVI image's strong resemblance to the GV1 plus GV2 image suggests that NDVI responds to more factors than does GV1 or GV2 singly.

NDVI does not significantly separate grazed from ungrazed watersheds, again possibly because many of the grazed watersheds are along the creeks and include trees, which inflate the NDVI values at the pixel scale. The significant interaction between grazing and burn treatments detected by NDVI in the ANOVA may be due to the fact that NDVI values for burned and unburned grazed watersheds are close to each other because of the influence of trees in those watersheds on NDVI.

Leaf area (GV1), greenness (GV2), and fractional cover $(\mathrm{GV} 3)$ were three vegetation attributes at the landscape scale that could be distinguished through LSMA across treated watersheds.

GV1's fractions responded consistently to changes in LAI throughout the image. In grazed watersheds (e.g., N20A in Fig. 4b), the GV1 fraction image has small values in those regions of the watershed devoid 


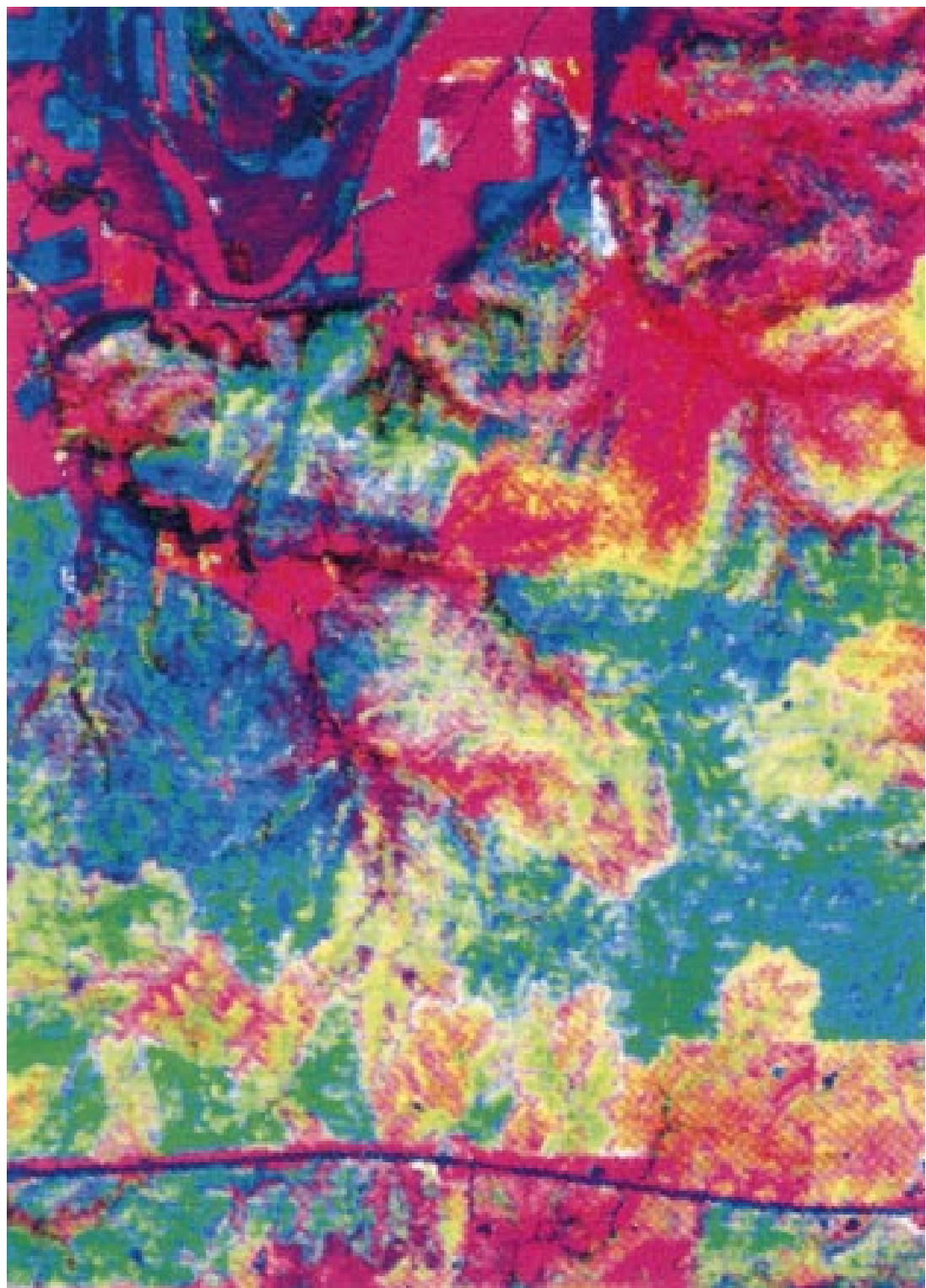

FIG. 9. Red-green-blue color composite based on endmember fractions. Red, nonphotosynthetic vegetation (NPV); green, grass (GV1 plus GV3); and blue, soil.

TABLE 7. Pearson's correlation coefficient $(R)$ for the relationship between ground measures of graminoid biomass and subsets of eigenvector (Eig) scores. The columns represent eigenvector subsets and each entry is the significance of the eigenvector (if relevant) in the regression.

\begin{tabular}{lccccccccc}
\hline \hline & Eig1 & Eig2 & Eig3 & Eig4 & Eig5 & Eig6 & All Eig & Eig1-4 & Eig5-6 \\
& $R=$ & $R=$ & $R=$ & $R=$ & $R=$ & $R=$ & $R=$ & $R=$ & $R=$ \\
& -0.63 & 0.22 & 0.25 & -0.39 & 0.11 & -0.67 & 0.92 & 0.68 & 0.91 \\
\hline Eig1 & 0.03 & & & & & & 0.97 & 0.13 & \\
Eig2 & & 0.49 & & & & & 0.77 & 0.89 & \\
Eig3 & & & 0.44 & & & & 0.62 & 0.97 & \\
Eig4 & & & & 0.22 & & & 0.85 & 0.47 & \\
Eig5 & & & & & 0.73 & & 0.12 & & 0.0018 \\
Eig6 & & & & & & 0.02 & 0.05 & & 0.0001 \\
\hline
\end{tabular}


TABLE 8. Eigenvector scores for the seven selected endmembers.

\begin{tabular}{lrrrrrr}
\hline \hline $\begin{array}{c}\text { Image } \\
\text { variable }\end{array}$ & Eig1 & Eig2 & Eig3 & Eig4 & Eig5 & Eig6 \\
\hline GV1 & -384 & 2225 & -17 & -247 & 230 & 36 \\
GV2 & 304 & 354 & 139 & 182 & -137 & 207 \\
GV3 & -234 & 627 & -50 & 24 & -21 & -38 \\
NPV & 4412 & 2076 & -859 & -182 & 112 & 81 \\
Soil & 743 & -1567 & 177 & -102 & -130 & -9 \\
Rock & 5034 & 2762 & 1027 & 2037 & 814 & 454 \\
Shade & -2730 & -3299 & 142 & 142 & 51 & -7 \\
\hline
\end{tabular}

of trees. The burned areas, which consist predominantly of taller $\mathrm{C}_{4}$ grasses, exhibited larger GV1 fractions than the unburned areas where vegetation growth was constrained by the litter layer (Knapp and Seastedt 1986, Knapp et al. 1993). The high NIR plateau of the GV1 endmember was a response to LAI, since NIR reflectance increases (up to saturation) with increasing leaf layers. Although deciduous trees may have a lower NIR plateau when measured at the canopy level rather than the leaf or branch level (e.g., Williams 1991), the GV1 endmember continued tracking LAI across changes in architecture, i.e., herbs to trees. If shadowing is a major reason for decreased NIR reflectance at the canopy level, as suggested in Williams (1991), the removal of shadowing and shade through a shade endmember would explain large GV1 fraction values associated with the trees. Like NDVI, GV1 fractions had a low correlation with ground-measured biomass values probably because of sensitivity to trees.

GV2's relationship to greenness was supported by its distinctive spectral signature, which displays marked green reflectance and red absorbance, and by its highly significant separation of grazing treatments. GV2 values range from low values in ungrazed watersheds to high values in grazed watersheds. Removal of biomass through grazing results in higher concentrations of nitrogen in remaining aboveground tissues (Dyer et al. 1991). Equating GV1 with LAI and GV2 with greenness explains the resemblance between the GV1 plus GV2 image and NDVI's image.

GV3's significant correlation with graminoid biomass and its lack of response to trees in the image confirms it as a measure of grass. For these reasons, GV3 is identified as the grass endmember, and as such, measures grass cover. GV3 fractions separate grazed from ungrazed treatments with high significance, but unlike the GV2 fractions, GV3 fractions were larger in the ungrazed than grazed watersheds. Moderate levels of grazing create a patchy landscape through selective feeding patterns (Hobbs et al. 1991, Vinton et al. 1993); thus GV3 fractions were lower for grazed areas and higher for the continuous cover of ungrazed watersheds.

Theoretically, green vegetation fractions relate to areal greenness and not directly to biomass volume. Graminoid biomass had a stronger correlation with GV1 plus GV3 fractions $(R=0.74)$ than with GV3 fractions alone $(R=0.69)$, probably because the combination of LAI (GV1) and cover (GV3) brought the estimates closer to a volume measurement. For the same reason, GV1 plus GV3 significantly discriminated all treatment effects and their interactions at the watershed scale, although GV3 did not discriminate between burning treatments.

If we consider the interpretation of GV1 as LAI and GV3 as grass cover to be valid, the image analysis substantiates ground studies and implies that landscape effects are carried over from the smaller scales and are detectable from remote sensors. LAI is most significantly affected by burn treatments, as burning substantially changes initial and subsequent growing conditions in the microclimate, vegetation composition, and nutrient cycling (Old 1969, Kucera 1981, Risser and Parton 1982, Knapp 1984, 1985, Ojima et al. 1990, Collins 1992, Knapp et al. 1993). Grazing will also affect LAI through biomass removal; however, in this analysis, the high values of trees present in grazed watersheds compensated for lowered grass LAI in the overall watershed means. Variation in fractional cover is created through grazing, leading from relatively continuous cover in any non-grazed area to significant patchiness in grazed areas.

The interaction of these two variables with respect to mixed treatment practices may be a result of the burning-grazing chronology. Burning in the spring resets the landscape from any prior condition to one of homogeneous, continuous cover. Subsequent grazing results in a discontinuous canopy. Moreover, Vinton et al. (1993) recently found that grazed patches were larger in more frequently burned watersheds than in less frequently burned areas of the Konza Prairie. Overall, the combination of the burning-grazing sequence creates the lowest cover of grass, followed by an unburned-ungrazed condition, as shown in Figs. 4 and 7. In the latter condition, lower production of grass can be expected due to accumulated litter and its influence on germination and growth. Burned, ungrazed treatments resulted in highest values for the LAI-fractional cover combination, followed by unburned, grazed treatments. In other words, optimum cover conditions appear to be created by single treatments, either grazed or burned, through their respective methods of removing or reducing litter buildup.

Because litter distribution (NPV) and soil exposure 
are descriptive of treatment response, the fractional abundances of the soil and NPV endmembers were additional discriminators of burning and grazing. In some studies (Roberts 1991, Roberts et al. 1993), it has been difficult to unmix an image with both soil and NPV endmembers without obtaining an NPV fraction image that displays the high frequency spatial variability associated with noise from endmember mimics (Sabol et al. 1992). (Mimics occur when an endmember is almost a linear combination of the other endmembers or when an endmember cannot be differentiated from another endmember because of low spectral resolution.) With manual selection of endmembers, an NPV endmember, in fact, gives the sharpest delineation of the watersheds (Fig. 8a). The lignin-cellulose absorption feature at $1720 \mathrm{~nm}$ (Elvidge 1990, Wessman 1990, Gao and Goetz 1994) in the NPV endmember (Fig. 6) together with the strong correlation of its fractions with dead vegetation biomass (litter and current), identified it as a nonphotosynthetic vegetation spectrum. This feature is not present in the soil endmember and, in general, is less apparent in live vegetation due to the influence of water. (It is the distinctive chlorophyll feature that separates photosynthesizing vegetation from its background.)

Litter is a definitive characteristic of unburned areas, although values are somewhat suppressed when grazing occurs to reduce biomass accumulation (Hofstede et al. 1995). The projected mean NPV fractions from the two-way ANOVA show the same pattern (Table 3). In addition, the lowest values for the NPV fractions occur in burned areas with or without grazing present. The soil image distinguishes grazing treatments since soil exposure is created by the activities of grazers (Hofstede et al. 1995, Collins and Benning 1996; see also Table 3 for soil's significant separation of grazed from ungrazed treatments).

The color composite of GV1 plus GV3, NPV, and soil best shows the patchiness of the variables across the landscape (Fig. 9), particularly within grazed watersheds where soil and grass fractions vary most. This variation within components is neither captured in watershed averages, as in the comparisons with ground measured biomass, nor is it captured well by the NDVI. Single-value indices such as the NDVI may not capture the variation in landscape composition and it is such variation that will decrease NDVI's utility when conditions are changing, both spatially and temporally.

\section{Conclusion}

Patchiness, LAI, greenness, graminoid biomass, and soil and litter distribution are six remotely sensible landscape attributes of grasslands affected by grazing and fire management practices. With sub-pixel separation of important landscape components, spectral mixture analysis produced a suite of variables in oneto-one correspondence with these attributes. Because a complex of factors (LAI, greenness, FPAR) and landscape components (e.g., soil, litter, trees as well as grass) influence a single NDVI value, NDVI does not discriminate the treatments as well as the endmember fractions.

There were several characteristics of this study that were necessary for its success. First, the MNF noise reduction method produced cleaner data, increasing the number of relatively noise-free eigenvectors from four to six. As we showed, six eigenvectors are needed to obtain an endmember that discriminates grass from trees. Second, the manual selection of endmembers allowed us to construct from these eigenvectors seven endmembers to use in the mixture model. Finally, the use of high spectral resolution data enabled the discrimination between the NPV and other background endmembers based on lignin-cellulose absorption features only present in the litter. These landscape components have not typically been discriminated in broadband imagery such as Landsat Thematic Mapper.

Primary production of ecosystems may be reduced as a result of management practices or by local variation in the availability of other resources. The response to disturbance is likely to be expressed in a number of factors ranging from functional (e.g., FPAR) to structural characteristics (e.g., LAI, patchiness) of the landscape. A single-index remote sensing approach to the broad-scale assessment of these systems is inadequate. Spectral mixture analysis tracks indicator variables of managed grassland systems that reflect the current structure and state of the system. These variables can be used to set the conditions for numerical simulations of grassland dynamics, with implications for large-scale studies of disturbances, biogeochemical cycling, and future management procedures.

ACKNOWLEDGMENTS

This study was supported by a grant from NASA under the Earth Observing System (EOS) Interdisciplinary program (Grant NAGW-2662). We wish to thank John Adams, Greg Asner, David Schimel, Tim Seastedt, and Richard Waring for their reviews of the manuscript. We are grateful to the Konza Tallgrass Prairie LTER project and NASA's aircraft program for making these data available.

\section{Literature Cited}

Abrams, M. D., A. K. Knapp, and L. C. Hulbert. 1986. A ten-year record of aboveground biomass in Kansas tallgrass prairie: effects of fire and topographic position. American Journal of Botany 73:1509-1515.

Adams, J. B., D. E. Sabol, V. Kapos, R. A. Filho, D. A. Roberts, M. O. Smith, and A. R. Gillespie. 1995. Classification of multispectral images based on fractions of endmembers: application to land-cover change in the Brazilian Amazon. Remote Sensing of Environment 52:137-154.

Asrar, G., E. T. Kanemasu, G. P. Miller, and E. L. Weiser. 1986. Light interception and leaf area estimates from measurements of grass canopy reflectance. Institute of Electrical and Electronics Engineers Transactions on Geoscience and Remote Sensing GE-24(1):76-81.

Bark, D. 1987. Konza Prairie Natural Research Area, Kansas. Pages 45-50 in D. Greenland, editor. The climates of the Long-Term Ecological Research Sites. Institute of Arctic and Alpine Research, Occasional Paper Number 44, University of Colorado, Boulder, Colorado, USA. 
Bartlett, D. S., G. J. Whiting, and J. M. Hartman. 1990. Use of vegetation indices to estimate intercepted solar radiation and net carbon dioxide exchange of a grass canopy. Remote Sensing of Environment 30:115-128.

Bateson, C. A., and B. Curtiss. 1996. A manual endmember selection method and spectral unmixing. Remote Sensing of Environment 55:229-243.

Benning, T. 1993. Fire frequency and topoedaphic controls of net primary productivity in the tallgrass prairie: development and tests of remote sensing indices. Dissertation. University of Colorado, Boulder, Colorado, USA.

Borel, C. B., and A. W. Gerstl. 1994. Nonlinear spectral mixing models for vegetative and soil surfaces. Remote Sensing of Environment 47:403-416.

Briggs, J. M., T. R. Seastedt, and D. J. Gibson. 1989. Comparative analysis of temporal and spatial variability in above-ground production in a deciduous forest and prairie. Holarctic Ecology 12:130-136.

Brown, M. J., and L. D. Bark. 1971. Drought in Kansas. Kansas Agricultural Experiment Station, Technical Bulletin, Number 547, Kansas State University of Agriculture and Applied Sciences, Manhattan, Kansas, USA.

Burke, I. C., T. G. F. Kittel, W. K. Laurenroth, P. Snook, C. M. Yonker, and W. J. Parton. 1991. Regional analysis of the Central Great Plains. BioScience 41:685-694.

Chapin, F. S., III, A. J. Bloom, C. B. Field, and R. H. Waring. 1987. Plant responses to multiple environmental factors BioScience 37:49-57.

Collins, S. L. 1992. Fire frequency and community heterogeneity in tallgrass prairie vegetation. Ecology 73:20012006.

Collins, S. L., and T. L. Benning. 1996. Spatial and temporal patterns in functional diversity. Pages 253-282 in K. Gaston, editor. Biodiversity: a biology of numbers and difference. Blackwell Scientific Publishers, London, U.K.

Dyer, M. I., C. L. Turner, and T. R. Seastedt. 1991. Mowing and fertilization effects on productivity and spectral reflectance in Bromus inermis plots. Ecological Applications 1:443-452.

Elvidge, C. D. 1990. Visible and near infrared reflectance characteristics of dry plant materials. International Journal of Remote Sensing 11(10): 1775-1795.

Gamon, J. A., C. B. Field, M. L. Goulden, K. L. Griffin, A. E. Hartley, G. Joel, J. Penuelas, and R. Valentini. 1995 Relationships between NDVI, canopy structure, and photosynthesis in three Californian vegetation types. Ecological Applications 5:28-41.

Gamon, J. A., C. B. Field, D. A. Roberts, S. L. Ustin, and R. Valentini. 1993. Functional patterns in an annual grassland during an AVIRIS overflight. Remote Sensing of Environment 44:239-235.

Gao, B.-C., and A. F. H. Goetz. 1994. Extraction of dry leaf spectral features from reflectance spectra of green vegetation. Remote Sensing of Environment 47(3):369-374.

Gao, B.-C., K. B. Heidebrecht, and A. F. H. Goetz. 1993 Derivation of scaled surface reflectance from AVIRIS data. Remote Sensing of Environment 44(2):165-178.

Gates, D. M., H. J. Keegan, J. C. Schleter, and V. R. Weidner. 1965. Spectral properties of plants. Applied Optics 4(1) $11-20$.

Green, A. A., M. Berman, P. Switzer, and M. D. Craig. 1988. A transformation for ordering multi-spectral data in terms of image quality with implications for noise removal. Institute of Electrical and Electronics Engineers IEEE Transactions on Geoscience and Remote Sensing 26(1):65-74.

Hatfield, J. L., G. Asrar, and E. T. Kanemasu. 1984. Intercepted photosynthetically active radiation estimated by spectral reflectance. Remote Sensing of Environment 14: $65-75$.

Hayes, D. C., and T. R. Seastedt. 1987. Root dynamics of tallgrass prairie in wet and dry years. Canadian Journal of Botany 65:787-791.

Hobbs, N. T., D. S. Schimel, C. E. Owensby, and D. S. Ojima. 1991. Fire and grazing in the tallgrass prairie: contingent effects on nitrogen budgets. Ecology 72:1374-1382.

Hofstede, R. G. M., M. X. M. Castillo, and C. M. R. Osorio. 1995. Biomass of grazed, burned and undisturbed Paramo Grasslands, Columbia. Arctic and Alpine Research 27(1): $1-12$.

Holland, E. A., and J. K. Detling. 1990. Plant response to herbivory and belowground nitrogen cycling. Ecology 71: $1040-1049$

Huete, A. R., and R. D. Jackson. 1987. The suitability of spectral indices for evaluating vegetation characteristics on arid rangelands. Remote Sensing of Environment 23:213232.

Huete, A. R., R. D. Jackson, and D. R. Post. 1985. Spectral response of a plant canopy with different soil backgrounds. Remote Sensing of Environment 17:37-53.

Hulbert, L. C. 1988. Causes of fire effects in tallgrass prairie. Ecology 69:46-58.

Jackson, R. D., and P. J. Pinter. 1986. Spectral response of architecturally different wheat canopies. Remote Sensing of Environment 20:43-56.

Jackson, R. D., R. J. Reginato, P. J. Pinter, Jr., and S. B. Idso. 1979. Plant canopy information extraction from composite scene reflectance of row crops. Applied Optics 18:37753782

Jantz, D. R., R. F. Harner, H. T. Rowland, and D. A. Grier. 1975. Soil survey of Riley County and part of Geary County, Kansas. Soil Conservation Service, U.S. Department of Agriculture, Washington, D.C., USA.

Knapp, A. K. 1984. Post-burn differences in solar radiation, leaf temperature and water stress influencing production in a lowland tallgrass prairie. American Journal of Botany 71: 220-227.

. 1985. Effect of fire and drought on ecophysiology of Andropogon gerardii and Panicum virgatum in tallgrass prairie. Ecology 66:1309-1320.

Knapp, A. K., J. T. Fahnestock, J. T., S. P. Hamburg, L. B. Statland, T. R. Seastedt, and D. S. Schimel. 1993. Landscape patterns in soil-plant water relations and primary production in tallgrass prairie. Ecology 74:549-560.

Knapp, A. K., and R. T. Seastedt. 1986. Detritus accumulation limits productivity of tallgrass prairie. BioScience 36(10):662-668.

Kucera, C. L. 1981. Grasslands and fire. Pages 90-111 in Fire regimes and ecosystem properties. U.S. Department of Agriculture, Forest Service, General Technical Report WO-26, Washington, D.C., USA.

Lauenroth, W. K., and J. M. Paruelo. 1995. Regional patterns of normalized difference vegetation index in North American shrublands and grasslands. Ecology 76:1888-1898.

Ojima, D. S., W. J. Parton, D. S. Schimel, and C. E. Owensby. 1990. Simulated impacts of annual burning on prairie ecosystems. Pages 99-118 in S. L. Collins and L. L. Wallace, editors. Fire in North American tallgrass prairies. University of Oklahoma Press, Norman, Oklahoma, USA.

Ojima, D. S., D. S. Schimel, W. J. Parton, and C. E. Owensby. 1994. Long- and short-term effects of fire on nitrogen cycling in tallgrass prairie. Biogeochemistry 24:67-84.

Old, S. M. 1969. Microclimate, fire and plant production in an Illinois prairie. Ecological Monographs 39:355-384.

Paruelo, J. M., M. R. Aguilar, R. A. Golluscio, R. J. C. Leon, and G. Pujol. 1993. Environmental controls of NDVI dynamics in Patagonia based on NOAA-AVHRR satellite data. Journal of Vegetation Science 4(3):425-428.

Risser, P. G., and W. J. Parton. 1982. Ecological analysis of tallgrass prairie: nitrogen cycle. Ecology 63:1342-1352.

Roberts, D. A. 1991. Separating spectral mixtures of vege- 
tation and soils. Dissertation, University of Washington, Seattle, Washington, USA

Roberts, D. A., M. O. Smith, and J. B. Adams. 1993. Green vegetation, nonphotosynthetic vegetation, and soils in AVIRIS data. Remote Sensing of Environment 44:255-269.

Sabol, D. E., J. B. Adams, and M. O. Smith. 1992. Quantitative subpixel spectral detection of targets in multispectral images. Journal of Geophysical Research 97:26592672.

Schimel, D. S., T. G. F. Kittel, A. K. Knapp, T. R. Seastedt, W. J. Parton, and V. B. Brown. 1991. Physiological interactions along resource gradients in a tallgrass prairie. Ecology 72:672-684.

Seastedt, T. R., J. M. Briggs, and D. J. Gibson. 1991. Controls of nitrogen limitation in tallgrass prairie. Oecologia 87:72-79.

Seastedt, T. R., and A. K. Knapp. 1993. Consequences of nonequilibrium resource availability across multiple time scales: the transient maxima hypothesis. American Naturalist 141(4):621-633.

Sellers, P. J. 1985. Canopy reflectance, photosynthesis and transpiration. International Journal of Remote Sensing 6(8): 1335-1372.

1987. Canopy reflectance, photosynthesis, and transpiration. II. The role of biophysics in the linearity of their interdependence. Remote Sensing of Environment 21:143183.

Sellers, P. J., J. A. Berry, G. J. Collatz, C. B. Field, and F. G. Hall. 1992. Canopy reflectance, photosynthesis and transpiration III. A re-analysis using improved leaf models and a new canopy integration scheme. Remote Sensing of Environment 42:187-216.

Sellers, P. J., F. G. Hall, G. Asrar, D. E. Strebel, and R. E. Murphy. 1988. The First ISLSCP Field Experimen (FIFE). Bulletin of the American Meteorological Society 69(1):22-27.
Smith, M. O., J. B. Adams, and D. E. Sabol. 1994. Spectral mixture analysis-new strategies for the analysis of multispectral data. Pages 125-143 in J. Hill, and J. Megier, editors. Imaging spectrometry-a tool for environmental observations. Kluwer Academic, Boston, Massachusetts, USA.

Smith, M. O., S. L. Ustin, J. B. Adams, and A. R. Gillespie. 1990. Vegetation in deserts: I. A regional measure of abundance from multispectral images. Remote Sensing of Environment 31:1-26.

Towne, G., and C. E. Owensby. 1984. Long-term effects of annual burning at different rates on ungrazed Kansas tallgrass prairie. Journal of Range Management 37:392-397.

Turner, C. L., T. R. Seastedt, M. I. Dyer, T. G. F. Kittel, and D. S. Schimel. 1992. Effects of management and topography on the radiometric response of a tallgrass prairie. Journal of Geophysical Research 97:18 855-18 866.

Vane, G., R. O. Green, T. G. Chrien, H. T. Enmark, E. G. Hansen, and W. M. Porter. 1993. The Airborne Visible/ Infrared Imaging Spectrometer (AVIRIS). Remote Sensing of Environment 44:127-143.

Vinton, M. A., D. C. Hartnett, E. J. Finck, and J. M. Briggs. 1993. Interactive effects of fire, bison (Bison bison) grazing and plant community composition in tallgrass prairie. American Midland Naturalist 129:10-18.

Wessman, C. A. 1990. Evaluation of canopy biochemistry. Pages 135-156 in R. J. Hobbs and H. A. Mooney, editors. Remote sensing of biosphere functioning. Springer-Verlag, New York, New York, USA.

Williams, D. L. 1991. A comparison of spectral reflectance properties at the needle, branch, and canopy level for a selected conifer species. Remote Sensing of Environment 35:79-93.

Yoder, B. J., and R. H. Waring. 1994. The normalized difference vegetation index of small douglas-fir canopies with varying chlorophyll concentrations. Remote Sensing of Environment 49:81-91. 